Gomez, P.; von Gunten, A.; Danuser, B. Autonomic nervous system reactivity within the valence-arousal affective space: modulation by sex and age. International Journal of Psychophysiology 109: 51-62, 2016.

\begin{tabular}{|l|l|}
\hline Postprint version & Final draft post-refereeing \\
\hline Journal website & http://www.sciencedirect.com/science/journal/01678760 \\
\hline Pubmed link & $\underline{\text { http://www.ncbi.nlm.nih.gov/pubmed/27720997 }}$ \\
\hline DOI & $\underline{10.1016 / j . j \text {.jpsycho.2016.10.002 }}$ \\
\hline
\end{tabular}


AUTONOMIC ACTIVATION, EMOTION, SEX, and AGING

Autonomic nervous system reactivity within the valence-arousal affective space:

modulation by sex and age

\section{Patrick Gomez}

Institut universitaire romand de Santé au Travail (Institute for Work and Health), University of Lausanne and University of Geneva

Armin von Gunten

Service of Old Age Psychiatry, Department of Psychiatry, Lausanne University Hospital

\section{Brigitta Danuser}

Institut universitaire romand de Santé au Travail (Institute for Work and Health), University of Lausanne and University of Geneva 


\begin{abstract}
In the present study, we examined how sex and age shape cardiovascular, electrodermal, and pupillary reactivity to picture series within the valence-arousal affective space in a sample of 176 healthy younger, middle-aged, and older men and women. Across participants, heart rate (HR) decelerated with increasing self-reported unpleasantness, whereas skin conductance level (SCL) and pupil size (PS) increased with increasing self-rated arousal. Systolic (SBP) and diastolic (DBP) blood pressure increased with increasing self-rated arousal when valence was pleasant but much less when valence was unpleasant. Compared to women, men exhibited a stronger correlation between valence and HR and an SBP response characterized by larger increases for pleasant high-arousal states and lower change scores for unpleasant low- and high-arousal and pleasant low-arousal states. Men’s largest SCL change scores were for pleasant high-arousal states, whereas women's largest SCL change scores were for unpleasant high-arousal states. The arousal-PS relationship was stronger among women, in particular for unpleasant series. From younger to older age, there were decreases in the strength of the valence-HR, arousal-SCL, and arousal-PS relationships. Older adults had larger overall increases in SBP and DBP than younger adults, but the relationships with selfreported valence and arousal were not age dependent. We discuss how the observed sex and age effects may reflect sex and age differences in emotional processing and in basic autonomic nervous system functioning.
\end{abstract}

Keywords: age differences; cardiovascular reactivity; emotion; pupillary response; sex differences; skin conductance level 
Autonomic nervous system reactivity within the valence-arousal affective space:

modulation by sex and age

1. Introduction

At the level of subjective experience, valence summarizes how well one is feeling and ranges from pleasant/good to unpleasant/bad, whereas arousal refers to a sense of mobilization or energy and ranges from very calm/sleepy to very aroused/excited (Russell and Barrett, 1999). These two dimensions are supposed to define the engagement of two evolutionarily primitive motivational systems, an appetitive one associated with positive valence and approach motivation toward resources and a defensive one associated with negative valence and aversive motivation towards threats. Arousal describes the vigor of motivational activation (Lang and Bradley, 2010). With this model of emotion as the guiding theoretical framework, we aimed at investigating the reactivity of heart rate (HR), systolic and diastolic blood pressure (SBP, DBP), skin conductance level (SCL), and pupil size (PS) to series of affective pictures in healthy adults. Empirical evidence regarding response coherence among experiential and physiological response systems in emotion is mixed (Evers et al., 2014), and how this coherence is affected by individual factors is poorly understood, despite the importance of individual differences in emotion has been highlighted (Hamann and Canli, 2004). Therefore, we focused here on how these measures regulated by the autonomic nervous system (ANS) covary with self-reported valence and arousal and how sex and age modulate these relationships.

Reactions of most healthy individuals to appetitive (e.g., appetizing food, attractive nudes) and aversive (e.g., attacking humans, blood) pictures are supposed to index the early stage of approach and defense characterized primarily by orienting, attentive processing, and preparation for potential action (Lang and Bradley, 2010). ANS responses vary as a function of the valence and arousal level of affective pictures. HR deceleration, mediated primarily by 
increases in vagal tone (Campbell et al., 1997), is generally greater when viewing unpleasant, compared to either pleasant or neutral pictures and correlates positively with self-rated unpleasantness (Burriss et al., 2007; Gomez and Danuser, 2010; Greenwald et al., 1989; Lang et al., 1993). Blood pressure (BP) increases with increasing self-rated arousal (Gomez and Danuser, 2010) but may also depend on valence, showing larger increases in response to pleasant as opposed to unpleasant arousing material (Hempel et al., 2005; Hempel et al., 2007; Richter et al., 2011; Sarlo et al., 2005). Skin conductance, which depends on the activity of the sympathetically innervated eccrine glands, has been shown to correlate positively with self-reported arousal (Burriss et al., 2007; Gomez and Danuser, 2010; Gomez et al., 2004; Greenwald et al., 1989; Hempel et al., 2007; Lang et al., 1993; Neiss et al., 2009; Sanchez-Navarro et al., 2005). PS depends on the activity of the dilator and sphincter muscles of the iris, which are innervated by the sympathetic (SNS) and parasympathetic nervous system (PNS) branches, respectively. Most studies point to a positive correlation between PS and arousal (Bradley et al., 2008; Bradley et al., 2015; Bradley and Lang, 2015; Dietz et al., 2011; Henderson et al., 2014; Jin et al., 2015; Lemaire et al., 2014; but see Franzen et al., 2009), but the relationship between PS and self-rated valence and arousal remains to be explicitly tested.

Sex differences in emotion have been investigated and discussed from different points of view (e.g., biological, socio-cultural, evolutionary, Bradley et al., 2001b; Fischer, 2000; Rupp and Wallen, 2008; Troisi, 2000; Wood and Eagly, 2002). Women may show a stronger disposition to engage the defensive motivational system when exposed to aversive cues than men, whereas men may show a stronger disposition to engage the appetitive motivational system when exposed to appetitive material (Andreano et al., 2014; Bradley et al., 2001b; Gard and Kring, 2007; Grossman and Wood, 1993; Hamann et al., 2004; Hillman et al., 2004; Rupp and Wallen, 2008; Sabatinelli et al., 2004; Stevens and Hamann, 2012). However, this 
evidence is based primarily on studies with young adults, and whether sex differences in emotional reactivity observed among young adults persist, attenuate, or increase in later life is unclear (Burriss et al.; 2007; Denburg et al., 2003; Gavazzeni et al., 2008; Kunzmann and Grühn, 2005; Labouvie-Vief et al., 2003; Neiss et al., 2009; Seider et al., 2011).

Normal aging is associated with widespread biological changes, including changes of the ANS (Barnett et al., 1999; Matsukawa et al., 1996; Winn et al., 1994) that are likely to substantially influence neurophysiological responses of older adults to affective stimuli. However, age differences in patterns of neurophysiological activity may also reflect agerelated changes in emotional processing. The amygdala activity to unpleasant vs. pleasant pictures is reduced in older adults compared to younger adults, whereas unpleasant pictures induce greater prefrontal cortex activity compared with neutral stimuli in older individuals than in younger ones (Dolcos et al., 2014; Leclerc and Kensinger, 2011; Mather et al., 2004; Nashiro et al., 2012). These patterns of neural activity are consistent with an age-related positivity effect, i.e., an age-related increase in the preference for pleasant over unpleasant information in attention and memory (Reed et al., 2014).

It is unclear whether age differences in peripheral physiological reactivity consistent with an age-related positivity effect are also observed, and, more generally, whether late adulthood is associated with more, less, or similar activation of the appetitive and defensive systems than early adulthood. Compared to younger adults, older adults have been found to exhibit both blunted (e.g., Burriss et al., 2007; Smith et al., 2005; Tsai et al., 2000), augmented (e.g., Kunzmann and Grühn, 2005; Seider et al., 2011; Smith et al., 2005) and similar (e.g., Kunzmann et al., 2005; Kunzmann and Richter, 2009; Overbeek et al., 2012) physiological reactivity to affective challenges. A number of factors - including the specific emotional contexts or measures and whether or not age-associated differences in response magnitude or pattern are considered - may explain these differences (Levenson, 2000). 
The goal of the present study was to investigate the relationships between self-rated valence and arousal and HR, SBP, DBP, SCL, and PS and how these relationships are influenced by sex and age. Across subjects, we predicted HR deceleration to increase with increasing unpleasantness, and SBP, DBP, SCL, and PS changes to increase along the arousal dimension. We were uncertain as to whether SBP and DBP could be influenced by selfreported valence because of the mixed nature of the existing literature. Regarding sex effects, the primary question was whether there are sex differences in the relationship between selfrated affect and ANS activation consistent with the hypothesis that women respond with greater defensive reactivity to unpleasant arousing contents, and men respond with increased appetitive activation to pleasant arousing contents from early to late adulthood. Concerning age effects, our main question was whether advancing age is associated with a shift in appetitive activation relative to defensive activation in line with an age-related positivity effect. Because normal aging is accompanied by functional and anatomical changes of the ANS, we predicted that there would be significant age effects for all five physiological parameters. However, given mixed findings, we wondered whether the age group effect would concern the overall response magnitude (defined as the overall increase or decrease from baseline) and/or the response pattern within the valence-arousal affective space (defined as the relationship between self-reported affective ratings and ANS responses). Whether age effects would be different in magnitude and pattern for different ANS indices was treated as an exploratory issue.

\section{Method}

\subsection{Participants}

Participants were 75 men and 101 women belonging to three age groups: younger (ages 20-34 years), middle-aged (ages 40-54 years), and older (ages 60-74 years). Studies of aging and emotion often compare young adults with an older sample. With the inclusion of a middle- 
aged sample nonlinear age effects can be explored. Other sample characteristics are presented in Table 1. Three additional participants completed the study protocol, but their data were unusable due to procedural flaws. The study was approved by the local ethics committee.

A screening questionnaire was used to include only respondents who: (i) were proficient in French; (ii) had scores lower than 11 on the anxiety and depression scales of the Hospital Anxiety Depression Scale (Zigmond and Snaith, 1983, 14 items, example items "I get sudden feelings of panic”, “I still enjoy the things I used to enjoy”, Anxiety and Depression scale min $=0, \max =21$ ). This was done to avoid the experience of excessive emotional distress among vulnerable people; (iii) reported at least "satisfactory" current general health on a 5-point scale ranging from "very good” to "very bad”; (iv) were not pregnant or breastfeeding; (v) did not use recreational/illicit drugs; (vi) had normal or corrected-to-normal vision and did not suffer from color blindness; (vii) did not have a cardiac pacemaker; and (viii) were not currently under medical treatment for any psychiatric disorder.

The participants were well-functioning individuals as shown by several indices given in Table 1. Anxiety and depression scores were very low. Mental health, physical functioning, and general health perception were better than average scores of the general local population (Richard et al., 2000). Participants' mean scores of verbal fluency were above average compared to normative data (Tombaugh et al., 1999).

\subsection{Stimuli}

Stimuli were 84 pictures chosen from the International Affective Picture System (IAPS; Lang et al., 2005). They were arranged into 14 series each consisting of 6 different pictures. The series represented different thematic contents. Six series were expected to be pleasant, six unpleasant, and two neutral. Moreover, the six pleasant and the six unpleasant series were expected to vary in arousal from relatively low to high. The six pleasant contents were appetizing food, erotic heterosexual couples, pleasant family scenes, pleasant nature, romantic 
heterosexual couples, and sport scenes. The unpleasant contents included environmental contamination, human loss, mutilated/burned bodies, physical violence, sick/injured human beings, and suffering/dead animals. The two neutral series showed household objects and neutral human activities. All pictures were landscape in orientation. Using Adobe Photoshop, mean brightness of nine pictures was modified such that mean brightness across picture series was very similar. Brightness was defined as the mean RGB (red green blue) value for each pixel, averaged across all pixels. Values can range from 0 (black) to 255 (white) for each of the RGB components in a color picture. Mean brightness of the 14 series ranged from 99 to 112. The library numbers of the pictures are given in the supplementary material at (enter URL here).

\subsection{Measures}

ANS measures. The following ANS measures were assessed: heart rate (HR), systolic blood pressure (SBP), diastolic blood pressure (DBP), skin conductance level (SCL), and pupil size (PS). The cardiovascular parameters were measured beat-to-beat by finger-cuff photoplethysmography with the Finometer ${ }^{\mathrm{TM}}$ using a sampling rate of $200 \mathrm{~Hz}$ (FMS Finapres Medical Systems, Amsterdam, The Netherlands). The finger cuff was wrapped around the middle phalanx of the middle finger of the left hand, which lay on the table during the entire experiment.

SCL was recorded with two pre-wired $8 \mathrm{~mm}$ diameter Ag/AgCl electrodes filled with TD-246 Skin Conductance Electrode Paste (Med Associates Inc., St. Albans, VT) and placed on the hypothenar eminence of the left hand. The electrodes were connected to a digital amplifier that applied a constant $0.5 \mathrm{~V}$ electrode excitation (Contact Precision Instruments, London, UK). The sampling rate was $40 \mathrm{~Hz}$.

PS was recorded using a dark pupil remote eye tracking system (iView X, SensoMotoric Instruments, Teltow, Germany), which allows free movement of the head and uses infrared 
illumination and computer-based image processing. Images of the eye are analyzed in realtime by detecting the pupil, calculating the center, and eliminating artifacts. The eye tracking system recorded both horizontal (diaX) and vertical (diaY) pupil diameter in pixels (px) with a sampling rate of $50 \mathrm{~Hz}$.

Respiratory variables were also measured. The results for these measures are reported in Gomez et al. (2016).

Valence and arousal ratings. We used the pencil-and-paper version of the 9-point SelfAssessment Manikin (SAM, Lang et al., 2005) to register self-reports of valence and arousal (scale $\min =1, \max =9$ ). We scored valence and arousal ratings so that higher values indicated more positive and more aroused, respectively.

Self-rated health. A few days prior to the experimental session, participants filled in the Medical Outcomes Study 36-Item Short Form (SF-36, Ware and Sherbourne, 1992, scores between 0 and 100 with higher scores indicating better health), which was used to determine mental health (5 items), physical functioning (10 items), and general health perception (5 items).

Verbal fluency. Verbal fluency was assessed with the Animal Naming Task (1 minute, Kertesz, 1982). This test shows a strong association with general intellectual ability and has been extensively used with older adults (Lindenberger et al., 1993).

\subsection{Procedure}

Participants were run in individual sessions. The experiment took place in a windowless room with the same lighting conditions during the entire session for all participants. First, the experimenter provided the participants with an outline of the experimental procedure and an explanation of the measurements. They were told that 14 series, consisting of 6 pictures each, would be displayed on the screen in front of them. They were also informed that the pictures 
would depict life events, objects, and persons that could evoke positive and negative emotions. Then, participants filled out an informed consent.

After attaching the sensors, the picture presentation and the self-rating procedure were explained to the participants. It was clearly stated that the ratings should be performed quickly and spontaneously and reflect the emotions felt during picture viewing. Participants were also told to keep their left arm on the table and to avoid excessive body movements. Then, the eye tracking system was calibrated by having the participants fixate nine dots that appeared one after the other on the screen. Note that this calibration is important for accurate measurement of the eye gaze, which is not analyzed here, but is irrelevant for recording pupil diameter as the pupil is detected by the eye camera. Subsequently, participants were shown an exemplary series of images of mushrooms followed by the 14 series, each lasting 1 min $(10 \mathrm{~s}$ per picture), with 75-s pauses in between. Fourteen 10-s intervals before onset of each series were defined as baseline periods. The pictures were displayed on a 19-inch computer monitor placed at a viewing distance of about $70 \mathrm{~cm}$. After each series, participants gave one valence and one arousal rating reflecting their affective experience and then relaxed until the next series. Participants were instructed to look at the monitor at all times except when rating the series.

There were six different presentation orders of the series. These orders were constructed with the constraint that no more than two series of similar valence were presented consecutively. Further, we made sure that over the six presentation orders the same series was presented on average both at the beginning, in the middle, and in the final part of the experiment. These orders were counterbalanced across age groups and gender. For each of the six presentation orders of the fourteen series, the six pictures within each series were presented in one specific order. Across the six presentation orders of the series, the same picture was shown in first, second, third, fourth, fifth, and sixth position, respectively. 
Upon completing the picture viewing session, sensors were removed. After a 10-min break, the animal naming task was performed, together with other tasks that are irrelevant to the present report. Finally, the participants were debriefed, paid 100 Swiss francs, and thanked.

\subsection{Data reduction and response definition}

The software packages Beatscope 1.1a (FMS Finapres Medical Systems BV), Psylab 8 (Contact Precision Instruments), and BeGaze ${ }^{\mathrm{TM}} 3.4$ (SensoMotoric Instruments) were used to extract the cardiovascular parameters, SCL, and PS data, respectively. PS was computed as an ellipse area using the formula PS $=\operatorname{diaX} / 2 * \operatorname{diaY} / 2 * \pi$. The cardiovascular data were not available for five participants, and PS was not available for three participants.

Mean values of the ANS measures were calculated for each participant for the 10 -s period before onset of each picture series (baseline) and for the 60-s series. The baseline values were subtracted from the values of the stimulus intervals to compute change scores for each series. The use of change scores as measure of ANS reactivity was deemed appropriate on the basis of a test of correlated variances by Geenen and van de Vijver (1993) that showed no significant dependency between scores of the baseline periods and the series for any ANS measures. The baseline periods did not include the time that participants rated the previous series.

\subsection{Statistical analyses}

All analyses were performed using SPSS Statistics version 23 (IBM Corp., Armonk, NY, USA). An alpha level of .05 was used for all tests.

First, we evaluated differences between age groups and sexes in baseline ANS activity. Mean scores of the fourteen baseline intervals were calculated for each ANS measure and each participant and subjected to univariate ANOVAs with Age Group (3 levels: younger, middleaged, older) and Sex as between-subject factors. Body mass index (BMI) and Educational 
Level were also included. For significant Age Group effects, we report Bonferroni-adjusted pairwise comparisons of the estimated marginal means.

Second, linear mixed models (LMM) with marginal maximum likelihood estimation were calculated for each ANS variable to determine the ANS response pattern within the valencearousal model and evaluate the influence of age and sex. The predicted variable was the change scores of the ANS measures as defined above. First, we tested the model including a random intercept for each participant, in order to take into account the nested structure of the data, and four fixed effects for the factors of main interest valence ratings $V$, arousal ratings A, Age Group, and Sex (basic model). BMI and Educational Level were also included. V and A are the subjective valence and arousal judgments given by the participants centered around the respective grand mean. Significant effects for Age Group and Sex in this model indicate significant differences between age groups and sexes in the average level of ANS reactivity (i.e., response magnitude). Subsequently, we added the six two-way interactions $\mathrm{V} x \mathrm{~A}, \mathrm{~V} x$ Age Group, A x Age Group, V x Sex, A x Sex, and Age Group x Sex, the four three-way interactions V x Age Group x Sex and A x Age Group x Sex, V x A x Age Group, and V x A x Sex, and the four-way interaction V x A x Age Group x Sex, and then, removed from this model nonsignificant terms to obtain the final model. As measure of effect size, we report for each model conditional $\mathrm{R}^{2}\left(\mathrm{R}_{\mathrm{LMM(c)}}^{2}\right)$ as proposed by Nakagawa and Schielzeth (2013). $\mathrm{R}_{\text {LMM(c) }}^{2}$ indicates the variance explained by the full model.

For HR, SBP, and DBP, all aforementioned analyses were also performed after excluding individuals taking cardiovascular medication (four middle-aged and 21 older adults using primarily antihypertensive agents). For PS, Brightness of the pictures was also included in all analyses. For the sake of brevity, statistics for BMI, Educational Level, and Brightness are not reported as these variables served only as control variables. 
Twenty-one younger women were using hormonal contraception (HC), and 12 older women were on hormonal replacement therapy (HRT). We tested for main and modulatory effects of HC and HRT.

Finally, for ANS measures with significant Age Group or Sex effects in the LMM analyses, we performed complementary ANOVAs to determine whether there were Age Group and Sex differences for specific series. We reasoned that this information would help us better understand the origin of the observed effects in the LMM analyses and may also be valuable to those interested in the psychophysiological response to distinct thematic contents. For the sake of succinctness, we report only significant effects together with their corresponding partial eta squared.

\section{Results}

\subsection{Baseline means of the ANS variables}

There were age differences in the baseline means of all five variables, and men had higher baseline SCL than women. Means and statistics are reported in Table 2.

\subsection{Relationships between affective ratings and ANS responses and sex and age effects}

3.2.1 Heart rate (HR). The estimated models for HR are presented in Table 3. In the basic model, HR change scores increased with increasing pleasantness and were overall lower for younger participants compared to older participants. However, the effect of $\mathrm{V}$ on HR interacted significantly with both Age Group and Sex. As shown in Figure 1, the V estimate was highest (i.e., steeper slope) for younger adults and lowest for older adults and was higher for men than women. These Age Group and Sex effects combined so that all three age groups of male participants had a significant $\mathrm{V}$ effect, whose estimate decreased across age groups (younger: $\mathrm{V}$ estimate $=0.24, S E=0.08, p=.002 ;$ A estimate $=-0.10, S E=0.08, p=.24$; middle-aged: $\mathrm{V}$ estimate $=0.20, S E=0.06, p=.002 ;$ A estimate $=0.05, S E=0.07, p=.47$; 
older: $\mathrm{V}$ estimate $=0.10, S E=0.05, p=.032 ;$ A estimate $=-0.01, S E=0.06, p=.89$ ). Among females, the V effect was significant for the younger women (V estimate $=0.15, S E=0.07, p$ $=.044 ;$ A estimate $=0.05, S E=0.08, p=.53$ ), approached significance for the middle-aged women (V estimate $=0.10, S E=0.06, p=.066$; A estimate $=0.11, S E=0.06, p=.070)$ and was not significant for the older women (V estimate $=-0.02, S E=0.03, p=.54$; A estimate $=$ $0.05, S E=0.04, p=.22$ ). The three-way interactions V x Age Group x Sex, V x A x Age Group, V x A x Sex were not significant ( $p s>.33$ ), indicating that the modulatory effects of Age Group and Sex were not significantly dependent on each other or on arousal. When participants using cardiovascular medication were excluded from the analyses, the same pattern of effects was obtained.

3.2.2 Systolic and diastolic blood pressure (SBP, DBP). The estimated models for SBP and DBP are presented in Table 4. In the basic model, SBP change scores increased with increasing arousal and were overall lower for younger participants compared to the other two age groups and for men compared to women. However, when we tested for interactions, both the $\mathrm{V}$ x A interaction and the V x A x Sex interaction were significant. These effects indicate that the A effect was dependent on $\mathrm{V}$ and that this dependency was different for men and women. Figure 2 illustrates the estimated models for men and women, averaged across age groups. It can be seen that the change in SBP from low A to high A was larger the more V became positive, i.e., when $\mathrm{V}$ was unpleasant, the change in SBP along A was relatively small, whereas it was relatively large when V was pleasant. Moreover, this pattern was more evident among men than women, with men exhibiting a larger range of SBP changes along A for pleasant V. The V x A x Age Group x Sex interaction was not significant $(p=.87$ ) indicating that the difference between men and women in their SBP response pattern was not significantly modulated by age. 
In the basic model, DBP change scores increased with both increasing V and increasing A and were overall lowest for the younger participants and highest for the older participants. As for $\mathrm{SBP}$, the $\mathrm{V} \times \mathrm{A}$ interaction was also significant, but contrary to SBP, the $\mathrm{V} \times \mathrm{A} \times \mathrm{Sex}$ interaction did not reach significance $(p=.13)$. As shown in Figure 3, DBP change scores were lowest for pleasant and unpleasant low-arousal ratings and highest for pleasant higharousal ratings.

For both SBP and DBP, the interactions V x Age Group, A x Age Group, and V x A x Age Group were not significant $(p s>.32$ ), indicating that age had no modulatory effects. The analyses with only participants not using cardiovascular medication yielded the same pattern of findings as the analyses with the full sample for both SBP and DBP.

3.2.3 Skin conductance level (SCL). The estimated models for SCL are presented in Table 5. In the basic model, SCL change scores increased with increasing arousal. Furthermore, we found that the interactions A x Age Group and V x A x Sex were significant. The A x Age Group effect reflected a decrease in the A estimate (i.e., flatter slope) from younger to older adults (younger: $\mathrm{V}$ estimate $=-0.010, S E=0.008, p=.76$; A estimate $=0.039, S E=0.008, p$ $<.001$; middle-aged: $\mathrm{V}$ estimate $=0.001, S E=0.007, p=.84 ;$ A estimate $=0.027, S E=$ 0.007, $p<.001$; older: $\mathrm{V}$ estimate $=0.001, S E=0.003, p=.87$; A estimate $=0.011, S E=$ 0.004, $p=.024)$. The A x Age Group x Sex interaction and the V x A x Age Group were not significant ( $p s>.71$ ), indicating that the A x Age Group effect did not differ as a function of sex or self-rated V. Figure 4 illustrates the estimated models for men and women, averaged across age groups. It can be recognized that men demonstrated larger SCL increases along A when $\mathrm{V}$ was pleasant, whereas women had larger SCL increases along A when V was unpleasant. Consequently, men's largest SCL changes occurred for pleasant high-arousal states, whereas women's largest SCL changes occurred for unpleasant high-arousal states. The V x A x Age Group x Sex interaction was not significant $(p=.17)$. Figure 4 also shows 
that, on average, SCL decreased from baseline. This can be explained by the fact that SCL tends to decrease over time during blocks of pictures of the same affective valence. Importantly, this time-related effect does not significantly impact affective discrimination (Bradley et al., 1996).

3.2.4 Pupil size (PS). The estimated models for PS are presented in Table 6. As expected, PS change scores increased with increasing A. However, the effect of A was modulated by both Age Group and Sex. As illustrated in Figure 5, the arousal estimate was highest (i.e., steeper slope) for younger adults and lowest for older adults and was higher for women than men. These Age Group and Sex effects combined so that all three age groups of female participants had a significant A effect, whose estimate decreased across age groups (younger: V estimate $=-0.35, S E=0.54, p=.52 ;$ A estimate $=3.79, S E=0.60, p<.001$; middle-aged: $\mathrm{V}$ estimate $=$ $0.72, S E=0.46, p=.12 ;$ A estimate $=2.15, S E=0.52, p<.001 ;$ older: V estimate $=0.01, S E$ $=0.27, p=.96 ;$ A estimate $=1.18, S E=0.33, p<.001)$. Among men, the A effect was significant for the younger participants (V estimate $=0.03, S E=0.56, p=.96$; A estimate $=$ 2.69, $S E=0.60, p<.001)$ and the middle-aged participants (V estimate $=-0.10, S E=0.51, p$ $=.85$; A estimate $=1.25, S E=0.57, p=.030$ ) but was not significant for the older participants (V estimate $=0.14, S E=0.47, p=.77$; A estimate $=0.62, S E=0.60, p=.30)$. The A x Age Group $x$ Sex and the V x A x Age Group interactions were not significant ( $p s>$.53). The V x A x Sex interaction was not far from significance $(p=.15)$. Given our hypothesis about sex differences in defensive and appetitive activation, we deemed justified to explore whether the A x Sex interaction was more evident among the six pleasant or six unpleasant series. The A $\mathrm{x}$ Sex interaction was not significant among the pleasant contents (estimate $=-0.39, S E=0.76$, $p=.61$ ), whereas it was significant among the unpleasant contents (estimate $=-1.66, S E=$ $0.67, p=.013)$. This suggests that the overall A $\mathrm{x}$ Sex interaction was primarily driven by sex differences in response to the unpleasant series. 
3.2.5 Hormonal contraception (HC). Among younger women, the use of HC did not have any significant effects on the responses of HR ( $p s>.45)$, SBP ( $p s>.25)$, DBP ( $p s>.20$ ), $\operatorname{SCL}(p s>.47)$, and PS (ps $>.28)$.

3.2.6 Hormonal replacement therapy (HRT). Among older women, the use of HRT did not have any significant effects on the responses of HR ( $p s>.35)$, SBP ( $p s>.26)$, and DBP ( $p$ s > .61). There was a significant modulatory effect of HRT on the relationship between SCL change scores and A ( $p=.027)$. Women on HRT showed a stronger correlation between A and SCL change scores than women not on HRT. However, the impact of this effect on the analyses with the entire sample was minimal. The $p$-value of the V x A x Sex interaction of the model reported above was .038 when older women on HRT were excluded and .057 when older women not on HRT were excluded. The A x Age Group interaction was significant in both analyses $(p s<.01)$. Women on HRT had also a more positive correlation between selfrated V and PS than women not on HRT $(p=.004)$. Again, this effect had no appreciable influences on the models with the full sample. In both analyses without women on HRT and without women not on HRT, the A x Age Group interaction remained significant $(p s<.001)$ as well as the A $x$ Sex interaction ( $p s<.05)$.

\subsection{Sex and age effects on the ANS responses to specific series}

Significant Sex and Age Group effects for the psychophysiological responses to specific series are given in Table 7. Mean changes of the ANS variables and affective ratings by sex and age group for the fourteen picture series are provided as supplementary material at (enter URL here).

\section{Discussion}


As hypothesized, HR deceleration covaried with ratings of unpleasantness, and both SCL and PS increased as a function of judgments of arousal. SBP and DBP increased with increasing self-rated arousal for pleasant but much less for unpleasant valence so that the largest BP increases were observed for pleasant high-arousal states. Responses of all five ANS measures were influenced by sex and age, except DBP for which no sex effects were obtained.

\subsection{Sex differences in ANS activation}

Men exhibited a stronger valence-HR relationship with lower HR change scores for unpleasant series than women. In two studies, men exhibited a HR response pattern across valence more consistent with a linear decrease across pleasant, neutral, and unpleasant contents compared to women (Bianchin and Angrilli, 2012; Gomez and Danuser, 2010). In contrast, Bradley et al. (2001b) reported that college-aged women reacted with larger initial HR deceleration in response to unpleasant, neutral, and erotic pictures than their male counterparts. These authors interpreted the larger initial HR deceleration to unpleasant pictures among young women as a sign of increased defensive activation (enhanced fear bradycardia). This reasoning applied to our findings would imply that men rather than women activated more strongly their defensive system when looking at unpleasant series. However, this interpretation seems untenable considering that two of the three series characterized by significantly less deceleration among women than men were rated as either more unpleasant or arousing by women than by men.

According to the defense cascade model (Lang and Bradley, 2010), defense reactivity is organized along a threat imminence dimension. Whereas the cardiac response is initially decelerative as a threat is perceived but confrontation is not imminent, it then progressively shifts toward acceleration as the threat approaches and its circa-strike zone is reached (Bradley et al., 2001a). Accordingly, animal phobics respond with cardiac acceleration to pictures of feared animals (Globisch et al., 1999). The weaker valence-HR relationship 
observed among women may reflect a partial shift in the cardiac response from deceleration to acceleration to unpleasant mainly high-arousal contents in women (Sanchez-Navarro et al., 2006). The specific picture presentation used here (i.e., 1-min series of thematically related images), which differs from the presentation mode of the majority of other similar studies (i.e., single 6-s pictures) may contribute to this shift. Indeed, more prolonged duration of affective stimulation leads to progressively greater emotion intensity (Goldin et al., 2005), and women habituate more slowly than men to unpleasant stimulation as they show more persistent amygdala activation over repetitions of unpleasant pictures than men (Andreano et al., 2014). Another factor possibly influencing findings are differences among studies in the operationalization of HR reactivity.

Because the parasympathetic system dominates the control of cardiac chronotropy in response to sensory information, lower PNS outflow may explain the reduced HR deceleration among women in response to negatively valenced stimuli. Women's smaller HR deceleration when processing unpleasant contents may also be driven by larger SNS cardiac outflow. This idea is most strongly supported by our findings for the SCL response pattern (see below).

Relative to women, men exhibited higher SBP increases for pleasant high-arousal states and lower SBP change scores for several valence-arousal combinations in the pleasant lowarousal and unpleasant high- and low-arousal quadrants of the affective space., These findings suggest that men's BP reactivity is influenced by the affective tone of the pictures more than women’s BP reactivity (Cellini et al., 2015; Dan-Glauser and Gross, 2011, 2015; Gomez and Danuser, 2010; Hempel et al., 2007; Sarlo et al., 2005) but are only partly in line with the view of enhanced defensive activation among women and enhanced appetitive activation among men as both women's and men's largest SBP increase was for pleasant high-arousal contents. 
The autonomic regulation of the cardiovascular system differs between men and women. Studies on sex differences in HR variability (HRV) suggest that women have higher parasympathetic cardiac autonomic activity than men, whereas men have a preponderance of sympathetic over vagal control of cardiac function (Antelmi et al., 2004; Barnett et al., 1999; Dart et al., 2002; Kuo et al., 1999; Liao et al., 1995; Sloan et al., 2008). Animal studies have found that the ventricular beta-adrenergic receptor responsiveness is greater in males than females (Hoeker et al., 2014; McIntosh et al., 2011), whereas the anti-adrenergic effect of adenosine via the $A_{1}$ adenosine receptors is greater in females than males (McIntosh et al., 2011). Men and women also differ in alpha- and beta-adrenergic receptor sensitivity in the vasculature (Freedman et al., 1987; Kneale et al., 2000) and in the sympatho-hemodynamic balance controlling BP at rest and in response to sympathoexcitatory maneuvers (Hogarth et al., 2007; Joyner et al., 2015; Yang et al., 2013). Sex differences may also exist in the relative sensitivity of and balance between cardiac and sympathetic arterial baroreflexes (Barnes et al., 2012; Barnett et al. 1999; Christou et al., 2005; Dutoit et al. 2010; Hogarth et al., 2007), although the exact nature of these differences is still controversial (Joyner et al., 2015). Further investigation is needed to understand to what extent sex differences in basic regulation of the cardiovascular system contribute to sex effects in cardiovascular reactivity to affective pictures.

Men's and women's increase in SCL along the arousal dimension were differently modulated by valence. Women exhibited a steeper SCL increase with increasing arousal when valence was unpleasant, and their largest SCL changes were for contents rated as unpleasant and arousing. Men displayed a steeper SCL increase with increasing arousal when valence was pleasant, and their largest SCL changes were found for contents associated with pleasant high-arousal feelings. These results are in line with the hypothesis that across adulthood, women demonstrate enhanced defensive activation, whereas men exhibit enhanced appetitive 
activation. We are not aware of well-established basic sex differences in the regulation of the electrodermal activity that could explain our findings. Magnitude and direction of sex differences in electrodermal reactivity seem to depend on the nature of the stimulation (Boucsein et al., 2012).

Across age groups, women exhibited a stronger arousal-PS relationship than men mainly stemming from sex differences in reactivity to the unpleasant series. These findings also support the hypothesis that women exhibit stronger defensive activation in response to unpleasant contents than men across the adult lifespan. To the best of our knowledge, there are no fundamental biological sex differences in the regulation of the pupil that may be responsible for our findings (Winn et al., 1994). Thus, the observed sex differences in PS changes likely reflect differences in emotional processing.

Taken together, the observed sex effects in the ANS responses support the notion that, across adulthood, women respond more strongly to aversive arousing stimuli, whereas men respond more strongly to appetitive arousing stimuli. These psychophysiological findings accords well with a recent meta-analysis of neuroimaging studies indicating greater left amygdala response to negative emotional stimuli for women and greater left amygdala response to positive emotional stimuli for men (Stevens and Hamann, 2012). Increased neurobiological reactivity to unpleasant stimuli in women has been theorized to be linked to an increased risk of psychopathologies such as anxiety disorders and depression (Craske, 2003; Hyde et al., 2008). Both biological (e.g., genetic, hormonal, neural) and sociocultural (e.g., social learning and reinforcement) factors have been hypothesized to explain sex differences in reactions to emotional events (Bradley et al., 2001b; Fischer, 2000; Rupp and Wallen, 2008; Troisi, 2000; Wood and Eagly, 2002).

\subsection{Age differences in ANS activation}


The age effect on the response magnitude and pattern was not unitary across ANS measures Older adults exhibited overall less deceleration than younger adults, and the strength of the valence-HR relationship decreased across age groups with younger adults exhibiting significantly larger HR deceleration in response to unpleasant contents than both middle-aged and older adults. These results extend studies showing increasing age to be associated with less HR deceleration irrespective of the affective tone of the pictures (Burriss et al., 2007; Overbeek et al., 2012, Smith et al., 2005). Contrary to HR, age had an effect on SBP and DBP response magnitude but did not modulate the relationship between SBP/DBP and self-ratings of valence and arousal. No study had previously investigated age effects on BP reactivity to pictorial stimuli. Studies using other perceptual stimuli eliciting specific emotions found evidence of larger SBP increases in older as compared to younger adults (Seider et al., 2011; Sze et al., 2012) or no age differences (Kunzmann et al., 2005; Vieillard et al., 2015). Crosssectional and longitudinal studies showed that BP reactivity to a broad range of (stressful) emotional events increases with age (Uchino et al., 2005; Uchino et al., 2010). Finally, the strength of the arousal-SCL relationship and the arousal-PS relationship decreased across age groups. These findings are an important extension of previous work (Dietz et al., 2011; Gavazzeni et al., 2008; Lemaire et al., 2014; Neiss et al., 2009).

The observed age effects for all five ANS measures could be explained by biological changes that take place with advancing age in industrialized areas. Most relevant to the cardiovascular findings are the decline of the parasympathetic control of HR (Barnett et al., 1999; Bonnemeier et al., 2003; Fukusaki et al., 2000; Sloan et al., 2008; Umetani et al., 1998), which could explain damped HR deceleration in late adulthood, and the interrelated increase in arterial stiffness and decrease in cardiac baroreflex sensitivity (Fleenor, 2013; Matsukawa et al., 1996), which were shown to be associated with enhanced BP reactivity to emotional tasks in middle-aged and older individuals (Lipman et al., 2002). Age-related decreases in the 
density and number of active sweat glands and in their output may account for reduced electrodermal responsiveness in combination with changes in brain areas important for electrodermal activity (Boucsein et al., 2012). Finally, advancing age is characterized by more restricted range of pupil size change (Winn et al., 1994).

The present study provides no evidence that the relative activation of the appetitive and defensive systems at the level of ANS reactivity might substantially change with advancing age. In fact, the reduction in the strength of the arousal-SCL and arousal-PS relationships was not different depending on self-reported valence, and age had no modulatory effect on BP. Only the reduction in the strength of the valence-HR relationship across age group may reflect a progressive shift from cardiac deceleration to cardiac acceleration because of enhanced defensive activation across age groups. However, this remains speculative.

Seider et al. (2011) found that, compared to younger adults, older adults demonstrated greater physiological responses (in particular BP) to film clips depicting irreversible loss but not to film clips inducing disgust. This finding was interpreted as support for the notion that sadness reactivity is heightened in older age. There might be differential adult lifespan trajectories in the experience and associated physiological activation of some discrete emotions (Kunzmann et al., 2014) that are not captured by the valence-arousal dimensional perspective.

The valence-dependent age differences in the activation of brain structures involved in emotional processing (Dolcos et al., 2014; Leclerc and Kensinger, 2011; Mather et al., 2004; Nashiro et al., 2012) do not seem to translate into clear valence-dependent age differences in ANS reactivity. It is possible that the biological changes in ANS functioning associated with aging mentioned above completely override age differences in physiological reactivity resulting from age differences in emotional processing, which are likely be relatively small compared to the age-related biological changes. Future studies should address this important 
question by assessing simultaneously brain activity and physiological reactivity to affective stimuli in younger and older adults.

\subsection{Limitations and conclusion}

First, caution in interpreting our results is required regarding age-related vs. cohort effects. Research using sequential designs is needed. Second, the use of HC and HRT did not significantly influence the main findings. The inclusion of data on menstrual cycle/sex steroid hormone levels and adherence to gender- and age-related stereotypes/roles may refine the picture. Third, the present sample consisted of relatively affluent, educated, and almost exclusively Caucasian individuals of a highly industrialized western country. A question for future studies is the extent to which the present findings are valid in ethnically, socially, and culturally diverse populations. Finally, examining impedance-derived measures of cardiac output and total peripheral resistance, along with estimates of sympathetic (pre-ejection period) and parasympathetic (high-frequency HRV) cardiac control would shed light on the more specific processes underlying sex and age differences in cardiovascular reactivity to emotional stimuli.

In conclusion, men and women across adulthood exhibit different ANS response pattern within the valence-arousal affective space, which are partly consistent with the idea of increased activation of the defensive motivational system in response to unpleasant arousing contents among women and increased activation of the appetitive motivational system in response to pleasant arousing contents among men. With advancing age, the relationships between self-rated affect and HR, SCL, and PS become progressively weaker, whereas BP overall reactivity increases. There is no evidence that aging is associated with changes in the relative activation of the appetitive and defensive systems at the level of ANS reactivity within the valence-arousal model. 


\section{AUTONOMIC ACTIVATION, EMOTION, SEX, and AGING}

The findings of this study underscore the importance of considering sex and age and, more broadly, individual differences in understanding the psychophysiology of emotion (Hamann and Canli, 2004). They have implications for biopsychological models of emotion and for more applied research fields such as biofeedback and human-technology interaction. 


\section{AUTONOMIC ACTIVATION, EMOTION, SEX, and AGING}

\section{Author note}

Patrick Gomez, Institut universitaire romand de Santé au Travail (Institute for Work and Health); Armin von Gunten, Service of Old Age Psychiatry, Department of Psychiatry, Lausanne University Hospital; Brigitta Danuser, Institut universitaire romand de Santé au Travail (Institute for Work and Health), University of Lausanne and University of Geneva.

This research was supported by a grant of the Opo Stiftung (Zurich, Switzerland) to Patrick Gomez and Brigitta Danuser.

We thank Miryam Cornaz, Olivier Fortini, and Bérengère Philippon for their assistance in data collection, and Dimitra Philippou for helping with data reduction.

Correspondence concerning this article should be addressed to Patrick Gomez, Institut universitaire romand de Santé au Travail, Route de la Corniche 2, 1066 Epalinges-Lausanne, Switzerland. Phone: +41 2131449 88; E-mail: Patrick.gomez@hospvd.ch 


\section{References}

Andreano, J.M., Dickerson, B.C., Barrett, L.F., 2014. Sex differences in the persistence of the amygdala response to negative material. Soc. Cogn. Affect. Neurosci. 9, 1388-1394. doi: $10.1093 /$ scan/nst127

Antelmi, I., de Paula, R.S., Shinzato, A.R., Peres, C.A., Mansur, A.J., Grupi, C.J., 2004. Influence of age, gender, body mass index, and functional capacity on heart rate variability in a cohort of subjects without heart disease. Am. J. Cardiol. 93, 381-385. doi: 10.1016/j.amjcard.2003.09.065

Barnes, J.N., Matzek, L.J., Charkoudian, N., Joyner, M.J., Curry, T.B., Hart, E.C., 2012. Association of cardiac baroreflex sensitivity with blood pressure transients: influence of sex and menopausal status. Front. Physiol. 3, 187. doi: 10.3389/fphys.2012.00187

Barnett, S.R., Morin, R.J., Kiely, D.K., Gagnon, M., Azhar, G., Knight, E.L., Nelson, J.C., Lipsitz, L.A., 1999. Effects of age and gender on autonomic control of blood pressure dynamics. Hypertension 33, 1195-1200. doi: 10.1161/01.HYP.33.5.1195

Bianchin, M., Angrilli, A., 2012. Gender differences in emotional responses: a psychophysiological study. Physiol. Behav. 105, 925-932. doi: 10.1016/j.physbeh.2011.10.031

Bonnemeier, H., Richardt, G., Potratz, J., Wiegand, U.K., Brandes, A., Kluge, N., Katus, H.A., 2003. Circadian profile of cardiac autonomic nervous modulation in healthy subjects: differing effects of aging and gender on heart rate variability. J. Cardiovasc. Electrophysiol. 14, 791799.

Boucsein, W., Fowles, D.C., Grimnes, S., Ben-Shakhar, G., Roth, W.T., Dawson, M.E., Filion, D.L., Society for Psychophysiological Research Ad Hoc Committee on Electrodermal, M., 2012. Publication recommendations for electrodermal measurements. Psychophysiology 49, 10171034. doi: 10.1111/j.1469-8986.2012.01384.x 
Bradley, M.M., Codispoti, M., Cuthbert, B.N., Lang, P.J., 2001a. Emotion and motivation I: defensive and appetitive reactions in picture processing. Emotion 1, 276-298. doi:10.1037/15283542.1.3.276

Bradley, M.M., Codispoti, M., Sabatinelli, D., Lang, P.J., 2001b. Emotion and motivation II: sex differences in picture processing. Emotion 1, 300-319. doi:10.1037/1528-3542.1.3.300

Bradley, M.M., Costa, V.D., Lang, P.J., 2015. Selective looking at natural scenes: Hedonic content and gender. Int. J. Psychophysiol. 98, 54-58. doi: 10.1016/j.ijpsycho.2015.06.008

Bradley, M.M., Cuthbert, B.N., Lang, P.J., 1996. Picture media and emotion: effects of a sustained affective context. Psychophysiology 33, 662-670. doi: 10.1111/j.1469-8986.1996.tb02362.x

Bradley, M.M., Lang, P.J., 2007. Emotion and motivation,. In: Cacioppo, J.T., Tassinary, L.G., Berntson, G.G. (Eds.), Handbook of psychophysiology (3rd ed.), Cambridge University Press, New York, NY, pp. 581-607.

Bradley, M.M., Lang, P.J., 2015. Memory, emotion, and pupil diameter: Repetition of natural scenes. Psychophysiology 52, 1186-1193. doi: 10.1111/psyp.12442

Bradley, M.M., Miccoli, L., Escrig, M.A., Lang, P.J., 2008. The pupil as a measure of emotional arousal and autonomic activation. Psychophysiology 45, 602-607. doi: 10.1111/j.14698986.2008.00654.x

Burriss, L., Powell, D.A., White, J., 2007. Psychophysiological and subjective indices of emotion as a function of age and gender. Cogn. Emot. 21, 182-210. doi: 10.1080/02699930600562235

Campbell, B.A., Wood, G., McBride, T., 1997. Origins of orienting and defensive responses: An evolutionary perspective. In: Lang, P.J., Simons, R.F., Balaban, M.T. (Eds.), Attention and orienting: Sensory and motivational processes, Erlbaum, Hillsdale, NJ, pp. 41-67.

Cellini, N., de Zambotti, M., Covassin, N., Gallicchio, G., Stegagno, L., Sarlo, M., 2015. Reduced cerebral and cardiovascular hemodynamics during sustained affective stimulation in young 


\section{AUTONOMIC ACTIVATION, EMOTION, SEX, and AGING}

women with chronic low blood pressure. Physiol. Behav.143, 83-89. doi:10.1016/j.physbeh.2015.02.047

Christou, D.D., Jones, P.P., Jordan, J., Diedrich, A., Robertson, D., Seals, D.R., 2005. Women have lower tonic autonomic support of arterial blood pressure and less effective baroreflex buffering than men. Circulation 111, 494-498. doi: 10.1161/01.CIR.0000153864.24034.A6

Craske, M.G., 2003. Origins of phobias and anxiety disorders: Why women more than men?, Elsevier, Oxford, UK, 312 pp.

Dan-Glauser, E.S., Gross, J.J., 2011. The temporal dynamics of two response-focused forms of emotion regulation: Experiential, expressive, and autonomic consequences. Psychophysiology 48, 1309-1322. doi: 10.1111/j.1469-8986.2011.01191.x.

Dan-Glauser, E.S., Gross, J.J., 2015. The temporal dynamics of emotional acceptance: Experience, expression, and physiology. Biol. Psychol. 108, 1-12. doi: 10.1016/j.biopsycho.2015.03.005

Dart, A.M., Du, X.J., Kingwell, B.A., 2002. Gender, sex hormones and autonomic nervous control of the cardiovascular system. Cardiovasc. Res. 53, 678-687. doi: 10.1016/j.biopsycho.2015.03.005.

Denburg, N.L., Buchanan, T.W., Tranel, D., Adolphs, R., 2003. Evidence for preserved emotional memory in normal older persons. Emotion 3, 239-253. doi: 10.1037/1528-3542.3.3.239

Dietz, J., Bradley, M.M., Okun, M.S., Bowers, D., 2011. Emotion and ocular responses in Parkinson's disease. Neuropsychologia 49, 3247-3253. doi:10.1016/j.neuropsychologia.2011.07.029

Dolcos, S., Katsumi, Y., Dixon, R.A., 2014. The role of arousal in the spontaneous regulation of emotions in healthy aging: a fMRI investigation. Front. Psychol. 5, 681. doi: 10.3389/fpsyg.2014.00681

Dutoit, A.P., Hart, E.C., Charkoudian, N., Wallin, B.G., Curry, T.B., Joyner, M.J., 2010. Cardiac baroreflex sensitivity is not correlated to sympathetic baroreflex sensitivity within healthy, 
AUTONOMIC ACTIVATION, EMOTION, SEX, and AGING

young humans. Hypertension 56, 1118-1123. doi: 10.1161/HYPERTENSIONAHA.110.158329

Eisdorfer, C., Doerr, H.O., Follette, W., 1980. Electrodermal reactivity: an analysis by age and sex. J. Human Stress 6, 39-42. doi: 10.1080/0097840X.1980.9936107

Evers, C., Hopp, H., Gross, J.J., Fischer, A.H., Manstead, A.S.R., Mauss, I.B., 2014. Emotion response coherence: A dual-process perspective. Biol. Psychol. 98, 43-49. doi: 10.1016/j.biopsycho.2013.11.003

Fischer, A.H., 2000. Gender and emotion: Social psychological perspectives, Cambridge University Press, Cambridge, UK, 331 pp.

Fleenor, B.S., 2013. Large elastic artery stiffness with aging: novel translational mechanisms and interventions. Aging Dis. 4, 76-83.

Franzen, P.L., Buysse, D.J., Dahl, R.E., Thompson, W., Siegle, G.J., 2009. Sleep deprivation alters pupillary reactivity to emotional stimuli in healthy young adults. Biol. Psychol. 80, 300-305. doi:10.1016/j.biopsycho.2008.10.010

Freedman, R.R., Sabharwal, S.C., Desai, N., 1987. Sex differences in peripheral vascular adrenergic receptors. Circ. Res. 61, 581-585.

Fukusaki, C., Kawakubo, K., Yamamoto, Y., 2000. Assessment of the primary effect of aging on heart rate variability in humans. Clin. Auton. Res. 10, 123-130.

Gard, M.G., Kring, A.M., 2007. Sex differences in the time course of emotion. Emotion 7, 429-437. doi: 10.1037/1528-3542.7.2.429

Gavazzeni, J., Wiens, S., Fischer, H., 2008. Age effects to negative arousal differ for self-report and electrodermal activity. Psychophysiology 45, 148-151. doi: 10.1111/j.14698986.2007.00596.x

Geenen, R., van de Vijver, F.J.,1993. A simple test of the Law of Initial Values. Psychophysiology 30, 525-530. doi: 10.1111/j.1469-8986.1993.tb02076.x 
Globisch, J., Hamm, A.O., Esteves, F., Ohman, A., 1999. Fear appears fast: temporal course of startle reflex potentiation in animal fearful subjects. Psychophysiology 36, 66-75.

Goldin, P.R., Hutcherson, C.A., Ochsner, K.N., Glover, G.H., Gabrieli, J.D., Gross, J.J., 2005. The neural bases of amusement and sadness: a comparison of block contrast and subject-specific emotion intensity regression approaches. NeuroImage 27, 26-36. doi: 10.1016/j.neuroimage.2005.03.018

Gomez, P., Danuser, B., 2010. Cardiovascular patterns associated with appetitive and defensive activation during affective picture viewing. Psychophysiology 47, 540-549. doi: 10.1111/j.1469-8986.2009.00953.x

Gomez, P., Filippou, D., Pais, B., von Gunten, A., Danuser, B., 2016. Breathing and affective picture processing across the adult lifespan. Biol Psychol 116, 101-111. doi: 10.1016/j.biopsycho.2016.07.011

Gomez, P., Stahel, W.A., Danuser, B., 2004. Respiratory responses during affective picture viewing. Biol. Psychol. 67, 359-373. doi: 10.1016/j.biopsycho.2004.03.013

Greenwald, M.K., Cook, E.W., Lang, P.J., 1989. Affective judgment and psychophysiological response: Dimensional covariation in the evaluation of pictorial stimuli. J. Psychophysiol. 3, 51-64.

Grossman, M., Wood, W., 1993. Sex differences in intensity of emotional experience: a social role interpretation. J. Pers. Soc. Psychol. 65, 1010-1022. doi: 10.1037/0022-3514.65.5.1010

Hamann, S., Canli, T., 2004. Individual differences in emotion processing. Curr. Opin. Neurobiol. 14, 233- 238. doi: 10.1016/j.conb.2004.03.010

Hamann, S., Herman, R.A., Nolan, C.L., Wallen, K., 2004. Men and women differ in amygdala response to visual sexual stimuli. Nat. Neurosci. 7, 411-416. doi: 10.1038/nn1208 
Hempel, R.J., Tulen, J.H., van Beveren, N.J., Mulder, P.G., Hengeveld, M.W., 2007. Subjective and physiological responses to emotion-eliciting pictures in male schizophrenic patients. Int. J. Psychophysiol. 64, 174-183. doi:10.1016/j.ijpsycho.2007.01.008

Hempel, R.J., Tulen, J.H., van Beveren, N.J., van Steenis, H.G., Mulder, P.G., Hengeveld, M.W., 2005. Physiological responsivity to emotional pictures in schizophrenia. J. Psychiatr. Res. 39, 509-518. doi: 10.1016/j.jpsychires.2004.11.004

Henderson, R.R., Bradley, M.M., Lang, P.J., 2014. Modulation of the initial light reflex during affective picture viewing. Psychophysiology 51, 815-818. doi: 10.1111/psyp.12236

Hillman, C.H., Rosengren, K.S., Smith, D.P., 2004. Emotion and motivated behavior: postural adjustments to affective picture viewing. Biol. Psychol. 66, 51-62. doi: 10.1016/j.biopsycho.2003.07.005

Hoeker, G.S., Hood, A.R., Katra, R.P., Poelzing, S., Pogwizd, S.M., 2014. Sex differences in betaadrenergic responsiveness of action potentials and intracellular calcium handling in isolated rabbit hearts. PLoS ONE 9, e111411. doi: 10.1371/journal.pone.0111411

Hogarth, A.J., Mackintosh, A.F., Mary, D.A., 2007. Gender-related differences in the sympathetic vasoconstrictor drive of normal subjects. Clin. Sci. 112, 353-361. doi: 10.1042/CS20060288

Hyde, J.S., Mezulis, A.H., Abramson, L.Y., 2008. The ABCs of depression: Integrating affective, biological, and cognitive models to explain the emergence of the gender difference in depression. Psychol. Rev. 115, 291-313. doi: 10.1037/0033-295X.115.2.291

Jin, A.B., Steding, L.H., Webb, A.K., 2015. Reduced emotional and cardiovascular reactivity to emotionally evocative stimuli in major depressive disorder. Int. J. Psychophysiol. 97, 66-74. doi: 10.1016/j.ijpsycho.2015.04.014

Joyner, M.J., Barnes, J.N., Hart, E.C., Wallin, B.G., Charkoudian, N., 2015. Neural control of the circulation: how sex and age differences interact in humans. Compr. Physiol. 5, 193-215. doi: 10.1002/cphy.c140005 
Kertesz, A., 1982. Western Aphasia Battery, Psychological Corp., San Antonio, TX.

Kneale, B.J., Chowienczyk, P.J., Brett, S.E., Coltart, D.J., Ritter, J.M., 2000. Gender differences in sensitivity to adrenergic agonists of forearm resistance vasculature. J. Am. Coll. Cardiol. 36, 1233-1238. doi:10.1016/S0735-1097(00)00849-4

Kunzmann, U., Grühn, D., 2005. Age differences in emotional reactivity: the sample case of sadness. Psychol. Aging 20, 47-59. doi: 10.1037/0882-7974.20.1.47

Kunzmann, U., Kappes, C., Wrosch, C., 2014. Emotional aging: a discrete emotions perspective. Front. Psychol. 5, 380. doi: 10.3389/fpsyg.2014.00380

Kunzmann, U., Kupperbusch, C.S., Levenson, R.W., 2005. Behavioral inhibition and amplification during emotional arousal: a comparison of two age groups. Psychol. Aging 20, 144-158. doi: 10.1037/0882-7974.20.1.144

Kunzmann, U., Richter, D., 2009. Emotional reactivity across the adult life span: the cognitive pragmatics make a difference. Psychol. Aging 24, 879-889. doi: 10.1037/a0017347

Kuo, T.B., Lin, T., Yang, C.C., Li, C.L., Chen, C.F., Chou, P., 1999. Effect of aging on gender differences in neural control of heart rate. Am. J. Physiol. 277, H2233-2239.

Labouvie-Vief, G., Lumley, M.A., Jain, E., Heinze, H., 2003. Age and gender differences in cardiac reactivity and subjective emotion responses to emotional autobiographical memories. Emotion 3, 115-126. doi: 10.1037/1528-3542.3.2.115

Lang, P.J., Bradley, M.M., 2010. Emotion and the motivational brain. Biol. Psychol. 84, 437-450. doi: 10.1016/j.biopsycho.2009.10.007

Lang, P.J., Bradley, M.M., Cuthbert, B.N., 2005. International affective picture system (IAPS): Digitized photographs, instruction manual and affective ratings. Technical Report A-6. The Center for Research in Psychophysiology, University of Florida, Gainesville (FL). 
Lang, P.J., Greenwald, M.K., Bradley, M.M., Hamm, A.O., 1993. Looking at pictures: affective, facial, visceral, and behavioral reactions. Psychophysiology 30, 261-273. doi: 10.1111/j.14698986.1993.tb03352.x

Leclerc, C.M., Kensinger, E.A., 2011. Neural processing of emotional pictures and words: a comparison of young and older adults. Dev. Neuropsychol. 36, 519-538. doi: $10.1080 / 87565641.2010 .549864$

Lemaire, M., Aguillon-Hernandez, N., Bonnet-Brilhault, F., Martineau, J., El-Hage, W., 2014. Subjective and physiological emotional response in euthymic bipolar patients: A pilot study. Psychiatry Res. 220, 294-301. doi: 10.1016/j.psychres.2014.07.002

Levenson, R.W., 2000. Expressive, physiological, and subjective changes in emotion across adulthood. In: Qualls, S.H., Abeles, N. (Eds.), Dialogues about aging: Psychology responds to the aging revolution, American Psychological Association, Washington, DC, pp. 123-140.

Liao, D., Barnes, R.W., Chambless, L.E., Simpson, R.J., Jr., Sorlie, P., Heiss, G., 1995. Age, race, and sex differences in autonomic cardiac function measured by spectral analysis of heart rate variability--the ARIC study. Atherosclerosis Risk in Communities. Am. J. Cardiol. 76, 906912. doi:10.1016/S0002-9149(99)80260-4

Lindenberger, U., Mayr, U., Kliegl, R., 1993. Speed and intelligence in old age. Psychol. Aging 8, 207-220. doi: 10.1037/0882-7974.8.2.207

Lipman, R.D., Grossman, P., Bridges, S.E., Hamner, J.W., Taylor, J.A., 2002. Mental stress response, arterial stiffness, and baroreflex sensitivity in healthy aging. J. Gerontol. A Biol. Sci. Med. Sci. 57, B279-284. doi: 10.1093/gerona/57.7.B279

Nakagawa, S., Schielzeth, H., 2013. A general and simple method for obtaining $\mathrm{R}^{2}$ from generalized linear mixed-effects models. Methods Ecol. Evol. 4, 133-142. doi: 10.1111/j.2041210x.2012.00261.x 
Mather, M., Canli, T., English, T., Whitfield, S., Wais, P., Ochsner, K., Gabrieli, J.D., Carstensen, L.L., 2004. Amygdala responses to emotionally valenced stimuli in older and younger adults. Psychol. Sci. 15, 259-263. doi: 10.1111/j.0956-7976.2004.00662.x

Matsukawa, T., Sugiyama, Y., Mano, T., 1996. Age-related changes in baroreflex control of heart rate and sympathetic nerve activity in healthy humans. J. Auton. Nerv. Syst. 60, 209-212. doi:10.1016/0165-1838(96)00057-4

McIntosh, V.J., Chandrasekera, P.C., Lasley, R.D., 2011. Sex differences and the effects of ovariectomy on the beta-adrenergic contractile response. American journal of physiology. Heart Circ. Physiol. 301, H1127-1134. doi: 10.1152/ajpheart.00711.2010

Nashiro, K., Sakaki, M., Mather, M., 2012. Age differences in brain activity during emotion processing: reflections of age-related decline or increased emotion regulation? Gerontology 58, 156-163. doi: 10.1159/000328465

Neiss, M.B., Leigland, L.A., Carlson, N.E., Janowsky, J.S., 2009. Age differences in perception and awareness of emotion. Neurobiol. Aging 30, 1305-1313. doi: 10.1016/j.neurobiolaging.2007.11.007

Overbeek, T.J., van Boxtel, A., Westerink, J.H., 2012. Respiratory sinus arrhythmia responses to induced emotional states: effects of RSA indices, emotion induction method, age, and sex. Biol. Psychol. 91, 128-141. doi: 10.1016/j.biopsycho.2012.05.011

Reed, A.E., Chan, L., Mikels, J.A., 2014. Meta-analysis of the age-related positivity effect: age differences in preferences for positive over negative information. Psychol. Aging 29, 1-15. doi: $10.1037 / \mathrm{a} 0035194$

Richard, J., Bouzourène, K., Gallant, S., Ricciardi, P., Sudre, P., Iten, A., Burnand, B., 2000. Validation et normes du SF-36 dans la population du canton Vaud, Institut universitaire de médecine sociale et préventive (Raison de santé, 28), Lausanne, Switzerland. 
Richter, S., Deter, H.-C., Rudat, M., Schachinger, H., Zimmermann-Viehoff, F., Weber, C., 2011. Anger and cardiovascular startle reactivity in normotensive young males. Int. J. Psychophysiol. 79, 364-370. doi: 10.1016/j.ijpsycho.2010.12.004

Rupp, H.A., Wallen, K., 2008. Sex differences in response to visual sexual stimuli: A review. Arch. Sex. Behav. 37, 206-218. doi: 10.1007/s10508-007-9217-9

Russell, J.A., Barrett, L.F., 1999. Core affect, prototypical emotional episodes, and other things called emotion: dissecting the elephant. J Pers Soc Psychol 76, 805-819. doi: 10.1037//00223514.76.5.805

Sabatinelli, D., Flaisch, T., Bradley, M.M., Fitzsimmons, J.R., Lang, P.J., 2004. Affective picture perception: gender differences in visual cortex? Neuroreport 15, 1109-1112. doi: 10.1097/00001756-200405190-00005

Sanchez-Navarro, J.P., Martinez-Selva, J.M., Roman, F., 2005. Emotional response in patients with frontal brain damage: effects of affective valence and information content. Behav. Neurosci. 119, 87-97. doi: 10.1037/0735-7044.119.1.87

Sanchez-Navarro, J.P., Martinez-Selva, J.M., Roman, F., 2006. Uncovering the relationship between defence and orienting in emotion: cardiac reactivity to unpleasant pictures. Int. J. Psychophysiol. 61, 34-46. doi: 10.1016/j.ijpsycho.2005.10.023

Sarlo, M., Palomba, D., Buodo, G., Minghetti, R., Stegagno, L., 2005. Blood pressure changes highlight gender differences in emotional reactivity to arousing pictures. Biol. Psychol. 70, 188-196. doi: 10.1016/j.biopsycho.2005.01.005

Seider, B.H., Shiota, M.N., Whalen, P., Levenson, R.W., 2011. Greater sadness reactivity in late life. Soc. Cogn. Affect. Neurosci. 6, 186-194. doi: 10.1093/scan/nsq069

Sloan, R.P., Huang, M.H., McCreath, H., Sidney, S., Liu, K., Dale Williams, O., Seeman, T., 2008. Cardiac autonomic control and the effects of age, race, and sex: the CARDIA study. Auton. Neurosci. 139, 78-85. doi: 10.1016/j.autneu.2008.01.006 
Smith, D.P., Hillman, C.H., Duley, A.R., 2005. Influences of age on emotional reactivity during picture processing. J. Gerontol. B Psychol. Sci. Soc. Sci. 60, P49-56. doi: 10.1093/geronb/60.1.P49

Stevens, J.S., Hamann, S., 2012. Sex differences in brain activation to emotional stimuli: a metaanalysis of neuroimaging studies. Neuropsychologia 50, 1578-1593. doi: 10.1016/j.neuropsychologia.2012.03.011

Sze, J.A., Gyurak, A., Goodkind, M.S., Levenson, R.W., 2012. Greater Emotional Empathy and Prosocial Behavior in Late Life. Emotion 12, 1129-1140. doi: 10.1037/a0025011

Tombaugh, T.N., Kozak, J., Rees, L., 1999. Normative data stratified by age and education for two measures of verbal fluency: FAS and animal naming. Arch. Clin. Neuropsychol. 14, 167-177. doi: 10.1016/S0887-6177(97)00095-4

Troisi, A., 2001. Gender differences in vulnerability to social stress: a Darwinian perspective. Physiol. Behav. 73, 443-449.

Tsai, J.L., Levenson, R.W., Carstensen, L.L., 2000. Autonomic, subjective, and expressive responses to emotional films in older and younger Chinese Americans and European Americans. Psychol. Aging 15, 684-693. doi: 10.1037/0882-7974.15.4.684

Uchino, B.N., Birmingham, W., Berg, C.A., 2010. Are older adults less or more physiologically reactive? A meta-analysis of age-related differences in cardiovascular reactivity to laboratory tasks. J. Gerontol. B Psychol. Sci. Soc. Sci. 65B, 154-162. doi: 10.1093/geronb/gbp127

Uchino, B.N., Holt-Lunstad, J., Bloor, L.E., Campo, R.A., 2005. Aging and cardiovascular reactivity to stress: longitudinal evidence for changes in stress reactivity. Psychol. Aging 20, 134-143. doi: 10.1037/0882-7974.20.1.134

Umetani, K., Singer, D.H., McCraty, R., Atkinson, M., 1998. Twenty-four hour time domain heart rate variability and heart rate: relations to age and gender over nine decades. J. Am. Coll. Cardiol. 31, 593-601. doi:10.1016/S0735-1097(97)00554-8 
Vieillard, S., Harm, J., Bigand, E., 2015. Expressive suppression and enhancement during musicelicited emotions in younger and older adults. Front. Aging Neurosci. 7, 11. doi: 10.3389/fnagi.2015.00011

Ware, J.E., Jr., Sherbourne, C.D., 1992. The MOS 36-item short-form health survey (SF-36). I. Conceptual framework and item selection. Med. Care 30, 473-483. doi: 10.1097/00005650199206000-00002

Winn, B., Whitaker, D., Elliott, D.B., Phillips, N.J., 1994. Factors affecting light-adapted pupil size in normal human subjects. Invest. Ophthalmol. Vis. Sci. 35, 1132-1137.

Wood, W., Eagly, A.H., 2002. A cross-cultural analysis of the behavior of women and men: implications for the origins of sex differences. Psychol. Bull. 128, 699-727.

Yang, H., Drummer, T.D., Carter, J.R., 2013. Sex differences in sympathetic neural and limb vascular reactivity to mental stress in humans. Am. J. Physiol. Heart Circ. Physiol. 304, H436-443. doi: 10.1152/ajpheart.00688.2012

Zigmond, A.S., Snaith, R.P., 1983. The hospital anxiety and depression scale. Acta Psychiatr. Scand. 67, 361-370. doi: 10.1111/j.1600-0447.1983.tb09716.x 
AUTONOMIC ACTIVATION, EMOTION, SEX, and AGING

Table 1 Participants’ characteristics by sex and age group

\begin{tabular}{|c|c|c|c|c|c|c|c|c|}
\hline \multirow[b]{2}{*}{ Variable } & \multicolumn{4}{|c|}{ Men } & \multicolumn{4}{|c|}{ Women } \\
\hline & Younger & Middle-aged & Older & All & Younger & Middle-aged & Older & All \\
\hline Sample size (n) & 30 & 23 & 22 & 75 & 34 & 29 & 38 & 101 \\
\hline Age (years) & $26.4(0.9)$ & $47.0(0.8)$ & $66.6(0.9)$ & $44.5(2.0)$ & $26.7(0.8)$ & $46.7(0.9)$ & $66.1(0.6)$ & $47.3(1.7)$ \\
\hline \multicolumn{9}{|l|}{ Marital status (\#) } \\
\hline Single & 9 & 10 & 5 & 24 & 13 & 9 & 27 & 49 \\
\hline In a relationship & 20 & 13 & 17 & 50 & 21 & 20 & 11 & 52 \\
\hline \multicolumn{9}{|l|}{ Employment status (\#) } \\
\hline Student & 15 & 0 & 0 & 15 & 13 & 0 & 0 & 13 \\
\hline Working & 11 & 18 & 0 & 29 & 17 & 21 & 5 & 43 \\
\hline Unemployed & 3 & 5 & 1 & 9 & 4 & 8 & 0 & 12 \\
\hline Retired & 0 & 0 & 21 & 21 & 0 & 0 & 33 & 33 \\
\hline \multicolumn{9}{|l|}{ Educational level (\#) } \\
\hline Level I & 0 & 1 & 1 & 2 & 0 & 3 & 7 & 10 \\
\hline Level II & 4 & 13 & 11 & 28 & 12 & 15 & 19 & 46 \\
\hline Level III & 26 & 9 & 10 & 45 & 22 & 11 & 12 & 45 \\
\hline \multicolumn{9}{|l|}{ Self-reported health } \\
\hline Anxiety $_{\mathrm{b}}$ & $4.8(0.4)$ & $4.5(0.5)$ & $5.2(0.5)$ & $4.9(0.3)$ & $5.4(0.4)$ & $5.3(0.4)$ & $5.1(0.4)$ & $5.2(0.2)$ \\
\hline Depression $_{b}$ & $1.5(0.2)$ & $2.7(0.4)$ & $2.9(0.5)$ & $2.3(0.2)$ & $1.9(0.3)$ & $1.8(0.4)$ & $2.2(0.4)$ & $2.0(0.2)$ \\
\hline Mental health $_{\mathrm{c}}$ & $71(3)$ & $75(3)$ & $75(4)$ & $73(2)$ & $71(3)$ & $72(3)$ & $77(3)$ & $74(2)$ \\
\hline Physical functioning & $99(0)$ & $97(1)$ & $94(1)$ & $97(1)$ & $98(1)$ & $94(2)$ & $82(4)$ & $91(2)$ \\
\hline General health $_{c}$ & $82(2)$ & $81(3)$ & $74(3)$ & $79(2)$ & $82(2)$ & $82(3)$ & $80(3)$ & $81(2)$ \\
\hline \multicolumn{9}{|l|}{ Verbal fluency } \\
\hline Animal naming task $\mathrm{d}_{\mathrm{d}}$ & $23.6(1.2)$ & $21.6(1.2)$ & $23.4(1.3)$ & $22.9(0.7)$ & $23.7(1.0)$ & $24.8(1.2)$ & $20.9(0.9)$ & $23.0(0.6)$ \\
\hline BMI $\left(\mathrm{kg} / \mathrm{m}^{2}\right)$ & $23.0(0.5)$ & $24.0(0.8)$ & $26.3(0.9)$ & $24.3(0.4)$ & $21.4(0.4)$ & $22.1(0.5)$ & $22.5(0.5)$ & $22.0(0.3)$ \\
\hline
\end{tabular}

39 


\section{AUTONOMIC ACTIVATION, EMOTION, SEX, and AGING}

Notes for Table 1

a Educational level was divided into three categories: level I = no vocational training with or without practical on-the-job training; education level II: completed vocational training equivalent to apprenticeship or a degree judged equivalent; education level III: baccalaureate with or without later academic studies; values for age, self-reported health, verbal fluency, and body mass index (BMI) are means with SEs in brackets; в HADS (Zigmond and Snaith, 1983), scores between 0 and 21; c SF-36 (Ware and Sherbourne, 1992), scores between 0 and 100 with higher scores corresponding to better health; ${ }_{\mathrm{d}}$ (Kertesz, 1982), number of animal names in 1 minute. 
AUTONOMIC ACTIVATION, EMOTION, SEX, and AGING

Table 2 ANS baseline means for younger, middle-aged, and older men and women (SEs in parentheses) with F-values for the Age Group main effect and the Sex main effect

\begin{tabular}{|c|c|c|c|c|c|c|c|c|}
\hline \multirow[b]{2}{*}{ Variable } & \multicolumn{3}{|c|}{ Men } & \multicolumn{3}{|c|}{ Women } & \multirow{2}{*}{$\begin{array}{l}\text { Age Group } \\
\text { Main Effect }\end{array}$} & \multirow{2}{*}{$\begin{array}{c}\text { Sex } \\
\text { Main Effect }\end{array}$} \\
\hline & Younger & Middle-aged & Older & Younger & Middle-aged & Older & & \\
\hline HR (bpm) & $68.7(1.2)$ & $69.4(2.2)$ & $66.2(1.7)$ & $73.4(1.5)$ & 67.9 (1.9) & $66.0(1.1)$ & $\begin{array}{c}F(2,165)=7.46 \\
p=.001_{\mathrm{a}}, \eta_{\mathrm{p}}^{2}=.083\end{array}$ & $\begin{array}{c}F(1,165)=0.64 \\
p=.43, \eta_{\mathrm{p}}^{2}=.004\end{array}$ \\
\hline SBP (mmHg) & $114.2(2.1)$ & $121.4(2.5)$ & 130.9 (2.9) & 113.1 (1.9) & 123.5 (3.8) & 132.9 (3.9) & $\begin{array}{c}F(2,165)=15.19 \\
p<.001_{\mathrm{bcd}}, \eta_{\mathrm{p}}{ }^{2}=.156\end{array}$ & $\begin{array}{c}F(1,165)=0.04 \\
p=.84, \eta_{\mathrm{p}}^{2}=.000\end{array}$ \\
\hline DBP (mmHg) & $67.0(1.5)$ & $72.9(1.6)$ & $68.2(1.8)$ & $65.4(1.3)$ & $70.7(2.0)$ & $69.4(1.6)$ & $\begin{array}{c}F(2,165)=3.28 \\
p=.040_{\mathrm{e}}, \eta_{\mathrm{p}}{ }^{2}=.038\end{array}$ & $\begin{array}{c}F(1,165)=0.74 \\
p=.39, \eta_{p}^{2}=.004\end{array}$ \\
\hline $\mathrm{SCL}(\mu \mathrm{S})$ & $5.03(0.64)$ & $3.82(0.76)$ & $3.19(0.55)$ & $3.65(0.49)$ & $2.55(0.40)$ & $2.40(0.52)$ & $\begin{array}{c}F(2,170)=3.21 \\
p=.043, \eta_{\mathrm{p}}^{2}=.036\end{array}$ & $\begin{array}{c}F(1,170)=16.44 \\
p<.001, \eta_{\mathrm{p}}^{2}=.088\end{array}$ \\
\hline$P S\left(p x^{2}\right)$ & $138.7(8.1)$ & $112.2(7.2)$ & $115.8(6.1)$ & $151.6(7.3)$ & $121.9(5.5)$ & $106.0(4.6)$ & $\begin{array}{c}F(2,167)=8.06 \\
p<.001_{\mathrm{fg}}, \eta_{\mathrm{p}}{ }^{2}=.088\end{array}$ & $\begin{array}{c}F(1,167)=0.01 \\
p=.94, \eta_{\mathrm{p}}{ }^{2}=.000\end{array}$ \\
\hline
\end{tabular}




\section{AUTONOMIC ACTIVATION, EMOTION, SEX, and AGING}

\section{Notes for Table 2}

The reported means are the mean scores of the fourteen 10-s baseline intervals preceding each series. HR: heart rate; SBP: systolic blood pressure; DBP: diastolic blood pressure; SCL: skin conductance level; PS: pupil size. The reported Age Group and Sex effects are adjusted for BMI and educational level. a younger adults $>$ older adults, $p<.001, d=0.72$; b younger adults $<$ middle-aged adults, $p=.042, d=0.47$; c younger adults $<$ older adults, $p<.001, d=$ 1.04; ${ }_{\mathrm{d}}$ middle-aged adults $<$ older adults, $p=.008, d=0.58$; e younger adults $<$ middle-aged adults, $p=.036, d=0.48$; f younger adults $>$ middle-aged adults, $p=.010, d=0.56$; g younger adults $>$ older adults, $p<.001, d=0.72$. After excluding participants taking cardiovascular medication, there were two small changes in the results for BP: DBP, Age Group effect, $F(2$, $141)=2.58, p=.079, \eta_{\mathrm{p}}{ }^{2}=0.04 ;$ SBP, middle-aged adults $<$ older adults, $p=.079, d=0.49$. The age effects for baseline means are largely in line with previous work indicating that compared to young adults (generally $<35$ years old), older adults (generally $>60$ years old) in industrialized areas have lower resting/baseline HR (Antelmi et al., 2004), higher BP, in particular SBP (Kunzmann et al., 2005) , lower SCL (Boucsein et al., 2012; Kunzmann and Grühn, 2005; Tsai et al., 2000), and smaller PS (Winn et al., 1994). Compared to women, men have been found to exhibit higher resting SCL from early to late adulthood (Eisdorfer et al., 1980). 
AUTONOMIC ACTIVATION, EMOTION, SEX, and AGING

Table 3 Estimated models for the relationships between HR change scores and valence ratings, arousal ratings, age group, and sex

\begin{tabular}{|c|c|c|c|c|c|c|c|}
\hline \multirow[b]{2}{*}{$\begin{array}{l}\text { ANS } \\
\text { variable }\end{array}$} & \multicolumn{7}{|l|}{ Predictors } \\
\hline & Intercept & $\mathrm{V}$ & A & Age Group & Sex & V x Age Group & V x Sex \\
\hline $\mathrm{HR}_{1}$ & $\begin{array}{c}0.21(0.28) \\
p=.10\end{array}$ & $\begin{array}{c}0.10(0.02) \\
p<.001\end{array}$ & $\begin{array}{c}0.04(0.03) \\
p=.20\end{array}$ & $\begin{array}{c}\mathrm{Y}:-0.92(0.31) \\
\mathrm{M}:-0.19(0.30) \\
p=.009_{\mathrm{a}}\end{array}$ & $\begin{array}{c}\delta^{\lambda}:-0.41(0.26) \\
p=.12\end{array}$ & & \\
\hline $\mathrm{HR}_{2}$ & $\begin{array}{c}0.22(0.29) \\
p=.099\end{array}$ & $\begin{array}{c}-.02(0.04) \\
p<.001\end{array}$ & $\begin{array}{c}0.02(0.03) \\
p=.41\end{array}$ & $\begin{array}{c}\mathrm{Y}:-0.93(0.31) \\
\mathrm{M}:-0.19(0.31) \\
p=.008\end{array}$ & $\begin{array}{c}\widehat{J}:-0.42(0.26) \\
p=.11\end{array}$ & $\begin{array}{c}\mathrm{Y}: 0.16(0.05) \\
\mathrm{M}: 0.09(0.05) \\
p=.013\end{array}$ & $\begin{array}{c}\hat{\delta}: 0.12(0.05) \\
p=.008\end{array}$ \\
\hline
\end{tabular}




\section{AUTONOMIC ACTIVATION, EMOTION, SEX, and AGING}

Notes for Table 3

V: valence rating; A: arousal rating; 1 basic model with the main effects of the predictors $\mathrm{V}$, A, Age Group, and Sex; 2 model with significant interactions (see Figure 1 for the graphical representation). Estimates are adjusted for BMI and educational level. Estimates for Age Group and V x Age Group are differences of the younger group (Y) and middle-aged group (M) from the older group who is the reference set to zero. Estimates for Sex and V x Sex are differences of the male participants (ð) from the female participants who are the reference set to zero. The $p$ values are from the Type III tests of fixed effects. a Comparison of younger vs. older adults is significant at $p<.01 . \mathrm{R}_{\text {LMM(c) }}^{2}$ for $\mathrm{HR}_{1}$ and $\mathrm{HR}_{2}$ are .166 and .174 , respectively. 
AUTONOMIC ACTIVATION, EMOTION, SEX, and AGING

Table 4 Estimated models for the relationships between change scores in SBP and DBP and valence ratings, arousal ratings, age group, and sex

\begin{tabular}{|c|c|c|c|c|c|c|c|c|c|}
\hline \multirow[b]{2}{*}{$\begin{array}{l}\text { ANS } \\
\text { variables }\end{array}$} & \multicolumn{9}{|l|}{ Predictors } \\
\hline & Intercept & V & A & Age Group & Sex & $\mathrm{V} \times \mathrm{A}$ & V x Sex & A x Sex & V x A x Sex \\
\hline $\mathrm{SBP}_{1}$ & $\begin{array}{c}1.94(0.44) \\
p<.001\end{array}$ & $\begin{array}{c}0.08(0.04) \\
p=.053\end{array}$ & $\begin{array}{c}0.20(0.04) \\
p<.001\end{array}$ & $\begin{array}{c}\mathrm{Y}:-1.84(0.47) \\
\mathrm{M}:-0.62(0.47) \\
p=.001_{\mathrm{ab}}\end{array}$ & $\begin{array}{c}\delta:-0.86(0.40) \\
p=.034\end{array}$ & & & & \\
\hline $\mathrm{SBP}_{2}$ & $\begin{array}{c}2.06(0.44) \\
p<.001\end{array}$ & $\begin{array}{c}-0.02(0.05) \\
p=.38\end{array}$ & $\begin{array}{c}0.11(0.06) \\
p<.001\end{array}$ & $\begin{array}{c}\mathrm{Y}:-1.95(0.48) \\
\mathrm{M}:-0.63(0.47) \\
\quad p<.001\end{array}$ & $\begin{array}{c}\hat{\delta}:-0.78(0.41) \\
p=.058\end{array}$ & $\begin{array}{c}0.03(0.02) \\
p<.001\end{array}$ & $\begin{array}{c}\delta: 0.12(0.08) \\
p=.15\end{array}$ & $\begin{array}{c}\delta: 0.17(0.09) \\
p=.054\end{array}$ & $\begin{array}{c}\delta: 0.07(0.03) \\
p=.024\end{array}$ \\
\hline $\mathrm{DBP}_{1}$ & $\begin{array}{c}1.18(0.25) \\
p<.001\end{array}$ & $\begin{array}{c}0.07(0.02) \\
p=.002\end{array}$ & $\begin{array}{c}0.11(0.03) \\
p<.001\end{array}$ & $\begin{array}{c}\mathrm{Y}:-1.09(0.28) \\
\mathrm{M}:-0.48(0.27) \\
p=.001_{\mathrm{b}}\end{array}$ & $\begin{array}{c}\delta:-0.21(0.23) \\
p=.36\end{array}$ & & & & \\
\hline $\mathrm{DBP}_{2}$ & $\begin{array}{c}1.25(0.26) \\
p<.001\end{array}$ & $\begin{array}{c}0.06(0.02) \\
p=.016\end{array}$ & $\begin{array}{c}0.11(0.03) \\
p<.001\end{array}$ & $\begin{array}{c}\mathrm{Y}:-1.12(0.28) \\
\mathrm{M}:-0.47(0.27) \\
p<.001\end{array}$ & $\begin{array}{c}\delta:-0.24(0.23) \\
p=.31\end{array}$ & $\begin{array}{c}0.02(0.01) \\
p=.016\end{array}$ & & & \\
\hline
\end{tabular}




\section{AUTONOMIC ACTIVATION, EMOTION, SEX, and AGING}

Notes for Table 4

V: valence rating; A: arousal rating; 1 basic model with the main effects of the predictors $\mathrm{V}$, A, Age Group, and Sex; 2 model with significant interactions (see Figures 2 and 3 for the graphical representations). Estimates are adjusted for BMI and educational level. Estimates for Age Group are differences of the younger group (Y) and middle-aged group (M) from the older group who is the reference set to zero. Estimates for Sex, V x Sex, A x Sex, and V x A x Sex are differences of the male participants $(ð)$ from the female participants who are the reference set to zero. The $p$ values are from the Type III tests of fixed effects. a Comparison of younger vs. middle-aged adults is significant at $p<.05$. ${ }_{\mathrm{b}}$ Comparison of younger vs. older adults is significant at $p<.001 . \mathrm{R}_{\mathrm{LMM}(\mathrm{c})}^{2}$ for $\mathrm{SBP}_{1}, \mathrm{SBP}_{2}, \mathrm{DBP}_{1}$, and $\mathrm{DBP}_{2}$ are .150, .161, .150 , and .153, respectively. 
AUTONOMIC ACTIVATION, EMOTION, SEX, and AGING

Table 5 Estimated models for the relationships between change scores in SCL and valence ratings, arousal ratings, age group, and sex

\begin{tabular}{|c|c|c|c|c|c|c|c|c|c|c|}
\hline \multirow[b]{2}{*}{$\begin{array}{l}\text { ANS } \\
\text { variable }\end{array}$} & \multicolumn{10}{|l|}{ Predictors } \\
\hline & Intercept & $\mathrm{V}$ & A & Age Group & Sex & $\mathrm{V} \times \mathrm{A}$ & A x Age Group & V x Sex & A x Sex & V x A x Sex \\
\hline $\mathrm{SCL}_{1}$ & $\begin{array}{c}-0.136(0.043) \\
p<.001\end{array}$ & $\begin{array}{c}0.001(0.002) \\
p=.81\end{array}$ & $\begin{array}{c}0.023(0.003) \\
p<.001\end{array}$ & $\begin{array}{c}\mathrm{Y}:-0.107(0.047) \\
\mathrm{M}:-0.030(0.046) \\
p=.068\end{array}$ & $\begin{array}{c}\widehat{\lambda}:-0.051(0.039) \\
p=.20\end{array}$ & & & & & \\
\hline $\mathrm{SCL}_{2}$ & $\begin{array}{c}-0.138(0.043) \\
p<.001\end{array}$ & $\begin{array}{c}-0.002(0.003) \\
p=.82\end{array}$ & $\begin{array}{c}0.010(0.005) \\
p<.001\end{array}$ & $\begin{array}{c}\mathrm{Y}:-0.109(0.047) \\
\mathrm{M}:-0.033(0.046) \\
p=.066\end{array}$ & $\begin{array}{c}\delta:-0.041(0.040) \\
p=.31\end{array}$ & $\begin{array}{c}-0.001(0.001) \\
p=.29\end{array}$ & $\begin{array}{c}\text { Y: } 0.030(0.006) \\
\text { M: } 0.017(0.006) \\
p<.001\end{array}$ & $\begin{array}{c}\delta: 0.004(0.005) \\
p=.47\end{array}$ & $\begin{array}{c}\widehat{\delta}:-0.008(0.006) \\
p=.17\end{array}$ & $\begin{array}{c}\delta: 0.004(0.002) \\
p=.043\end{array}$ \\
\hline
\end{tabular}




\section{AUTONOMIC ACTIVATION, EMOTION, SEX, and AGING}

Notes for Table 5

$\mathrm{V}$ : valence rating; A: arousal rating; ${ }_{1}$ basic model with the main effects of the predictors $\mathrm{V}$, A, Age Group, and Sex; 2 model with significant interactions (see Figure 4 for the graphical representation). Estimates are adjusted for BMI and educational level. Estimates for Age Group and A x Age Group are differences of the younger group (Y) and middle-aged group (M) from the older group who is the reference set to zero. Estimates for Sex, V x Sex, A x Sex, and V x A x Sex are differences of the male participants $\left({ }^{\Uparrow}\right)$ from the female participants who are the reference set to zero. The $p$ values are from the Type III tests of fixed effects. $\mathrm{R}_{\text {LMM(c) }}^{2}$ for $\mathrm{SCL}_{1}$ and $\mathrm{SCL}_{2}$ are .361 and .372, respectively. 
AUTONOMIC ACTIVATION, EMOTION, SEX, and AGING

Table 6 Estimated models for the relationships between change scores in PS and valence ratings, arousal ratings, age group, and sex

\begin{tabular}{|c|c|c|c|c|c|c|c|}
\hline \multirow[b]{2}{*}{$\begin{array}{l}\text { ANS } \\
\text { variable }\end{array}$} & \multicolumn{7}{|l|}{ Predictors } \\
\hline & Intercept & V & A & Age Group & Sex & A x Age Group & A x Sex \\
\hline $\mathrm{PS}_{1}$ & $\begin{array}{c}-14.75(10.58) \\
p=.28\end{array}$ & $\begin{array}{c}0.13(0.19) \\
p=.50\end{array}$ & $\begin{array}{c}2.03(0.22) \\
p<.001\end{array}$ & $\begin{array}{c}\mathrm{Y}: 6.91(2.95) \\
\mathrm{M}: 3.00(2.91) \\
\quad p=.066\end{array}$ & $\begin{array}{c}\hat{\partial}:-2.82(2.48) \\
p=.26\end{array}$ & & \\
\hline $\mathrm{PS}_{2}$ & $\begin{array}{c}-12.94(10.53) \\
p=.37\end{array}$ & $\begin{array}{c}0.05(0.19) \\
p=.80\end{array}$ & $\begin{array}{c}1.33(0.39) \\
p<.001\end{array}$ & $\begin{array}{c}\text { Y: } 6.94(2.94) \\
\text { M: } 2.86(2.90) \\
p=.062\end{array}$ & $\begin{array}{c}0.73(2.47) \\
p=.27\end{array}$ & $\begin{array}{c}\mathrm{Y}: 2.43(0.49) \\
\mathrm{M}: 0.60(0.50) \\
p<.001\end{array}$ & $\begin{array}{c}\delta:-0.93(0.41) \\
p=.024\end{array}$ \\
\hline
\end{tabular}




\section{AUTONOMIC ACTIVATION, EMOTION, SEX, and AGING}

Notes for Table 6

$\mathrm{V}$ : valence rating; A: arousal rating; ${ }_{1}$ basic model with the main effects of the predictors $\mathrm{V}$, A, Age Group, and Sex; 2 model with significant interactions (see Figure 5 for the graphical representation). Estimates are adjusted for BMI, educational level, and picture brightness. Estimates for Age Group and A x Age Group are differences of the younger group (Y) and middle-aged group (M) from the older group who is the reference set to zero. Estimates for Sex and A x Sex are differences of the male participants ( $\overbrace{}^{A})$ from the female participants who are the reference set to zero. The $p$ values are from the Type III tests of fixed effects. $\mathrm{R}_{\text {LMM(c) }}^{2}$ for $\mathrm{PS}_{1}$ and $\mathrm{PS}_{2}$ are .256 and .267, respectively. 
Table 7 Significant Sex and Age Group effects for the psychophysiological responses to specific series

\begin{tabular}{|c|c|c|}
\hline Dependent measures & Effects & Series \\
\hline & Sex & \\
\hline HR & $\hat{0}<q$ & U: mutilated/burned bodies (.067), physical violence (.063), sick/injured human beings (.024) \\
\hline \multirow[t]{2}{*}{ SBP } & $\hat{0}<q$ & P: pleasant nature (.045); U: human loss (.025), suffering/dead animals (.037) \\
\hline & $\hat{0}>$ o & P: erotic heterosexual couples (.037) \\
\hline SCL & $\hat{0}<q$ & P: pleasant nature (.024); U: mutilated/burned bodies (.033) \\
\hline PS & $\hat{\sigma}<q$ & U: sick/injured human beings (.029) \\
\hline Valence rating & $\hat{0}>0$ & U: physical violence (.035), suffering/dead animals (.080) \\
\hline \multirow[t]{2}{*}{ Arousal rating } & $\hat{0}<q$ & U: mutilated/burned bodies (.026), physical violence (.031), suffering/dead animals (.049) \\
\hline & Age Group & \\
\hline HR & $\mathrm{Y}<\mathrm{O}$ & U: human loss (.059), mutilated/burned bodies (.025), physical violence (.032) \\
\hline SBP & $\mathrm{Y}<\mathrm{O}$ & $\begin{array}{l}\text { P: erotic heterosexual couples (.056), pleasant nature (.092), sport scenes }(.024) \text {; } \mathrm{N} \text { : household objects }(.024) \text {, neutral human activities }(.067) \text {; } \\
\text { U: human loss (.036), physical violence (.036), suffering/dead animals (.029) }\end{array}$ \\
\hline DBP & $\mathrm{Y}<\mathrm{O}$ & $\begin{array}{l}\text { P: erotic heterosexual couples (.029); pleasant nature (.049); N: household objects (.028), neutral human activities (.063); U: human loss (.037), } \\
\text { mutilated/burned bodies (.026), physical violence (.042) }\end{array}$ \\
\hline SCL & $\mathrm{Y}<\mathrm{O}$ & P: romantic heterosexual couples (.031), sport scenes (.066); N: household objects (.029), neutral human activities (.039) \\
\hline PS & $\mathrm{Y}>\mathrm{O}$ & P: erotic heterosexual couples (.076); U: sick/injured human beings (.030), suffering/dead animals (.052) \\
\hline \multirow[t]{2}{*}{ Valence rating } & $\mathrm{Y}<\mathrm{O}$ & P: pleasant family scenes (.045), pleasant nature (.052), romantic heterosexual couples (.066) \\
\hline & $\mathrm{Y}>\mathrm{O}$ & U: environmental contamination (.038), mutilated/burned bodies (.035), physical violence (.091) \\
\hline
\end{tabular}




\section{AUTONOMIC ACTIVATION, EMOTION, SEX, and AGING}

Notes for Table 7

HR: heart rate; SBP: systolic blood pressure; DBP: diastolic blood pressure; SCL: skin conductance level; PS: pupil size; Y: younger adults; O: older adults; $\overbrace{}^{\Uparrow}$ : male participants; $\bigcirc$ : female participants; P: pleasant series; N: neutral series; U: unpleasant series. Reported Sex and Age Group effects are significant at $p<.05$ and are based on comparisons of estimated marginal means adjusted for BMI and educational level. Partial eta squared is given in parentheses. 
AUTONOMIC ACTIVATION, EMOTION, SEX, and AGING

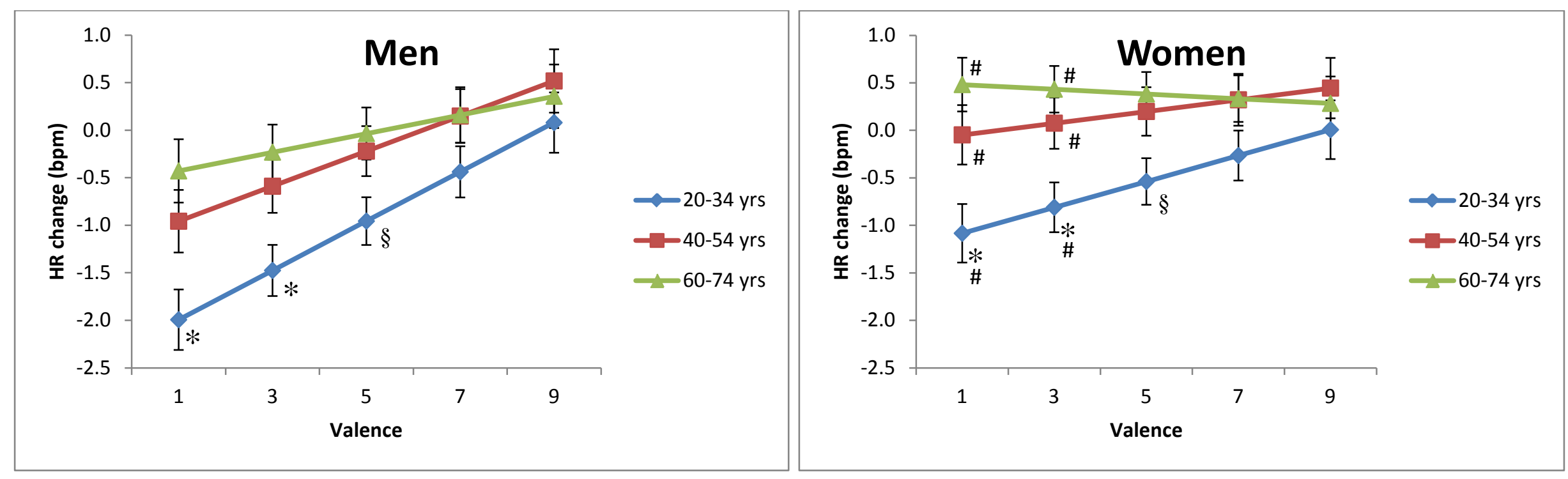

Figure 1 
AUTONOMIC ACTIVATION, EMOTION, SEX, and AGING

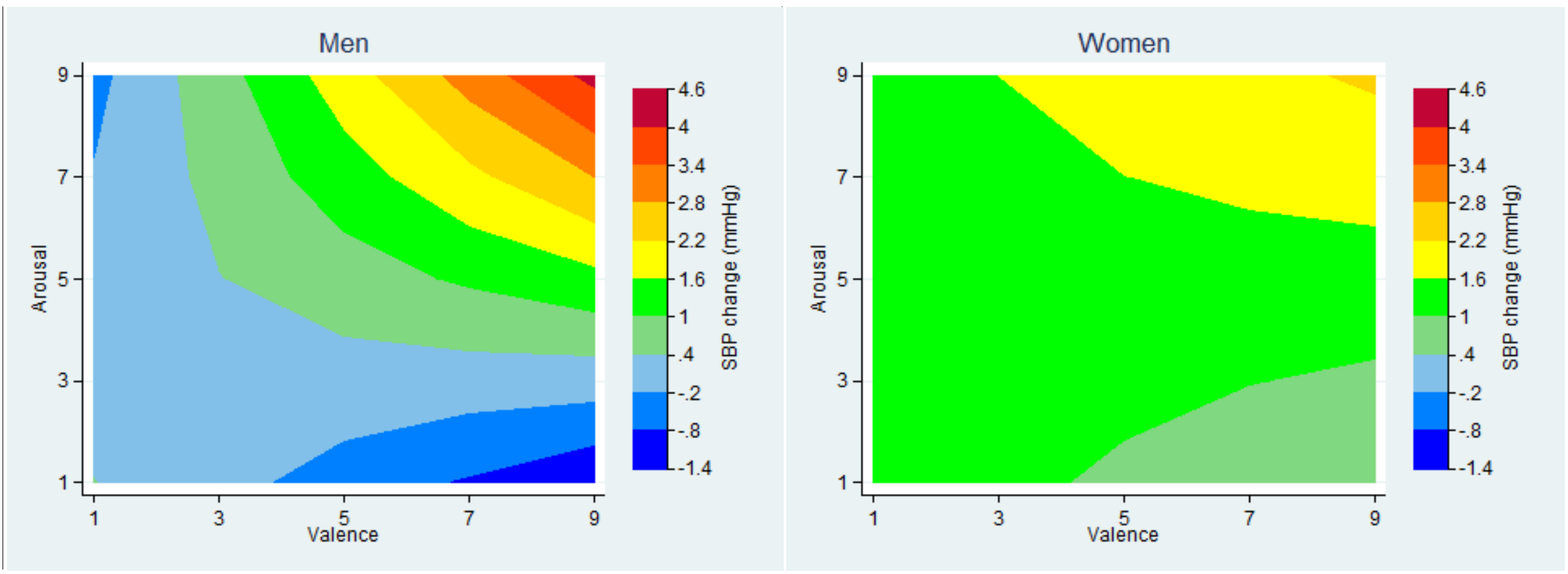

Figure 2 
AUTONOMIC ACTIVATION, EMOTION, SEX, and AGING

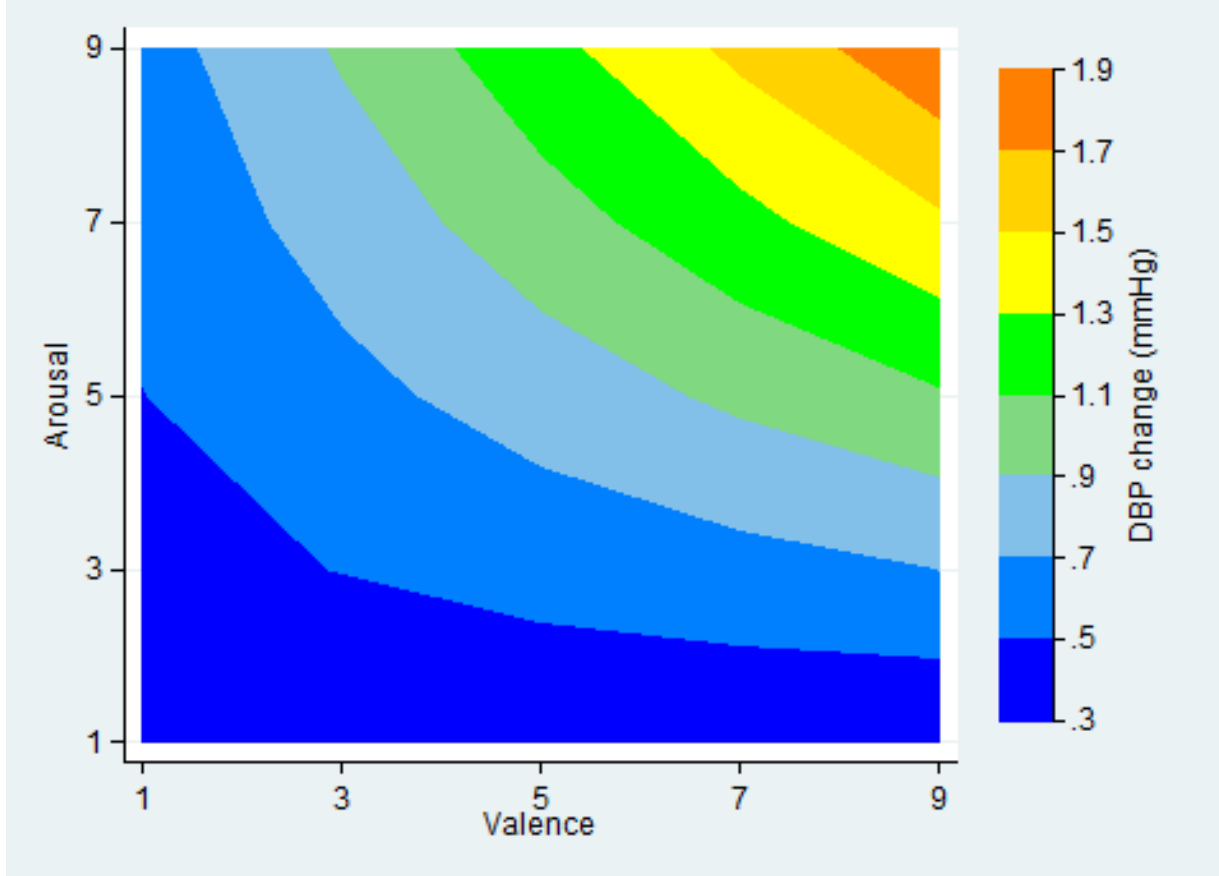

Figure 3 
AUTONOMIC ACTIVATION, EMOTION, SEX, and AGING

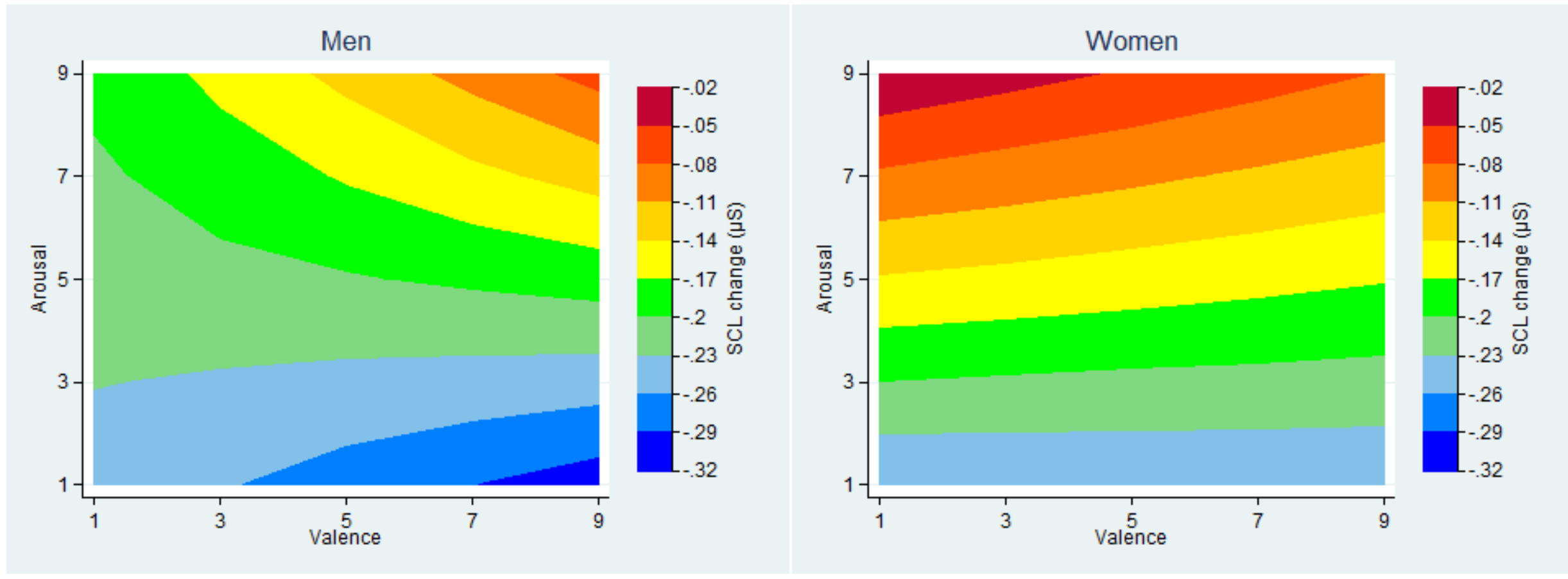

Figure 4 
AUTONOMIC ACTIVATION, EMOTION, SEX, and AGING

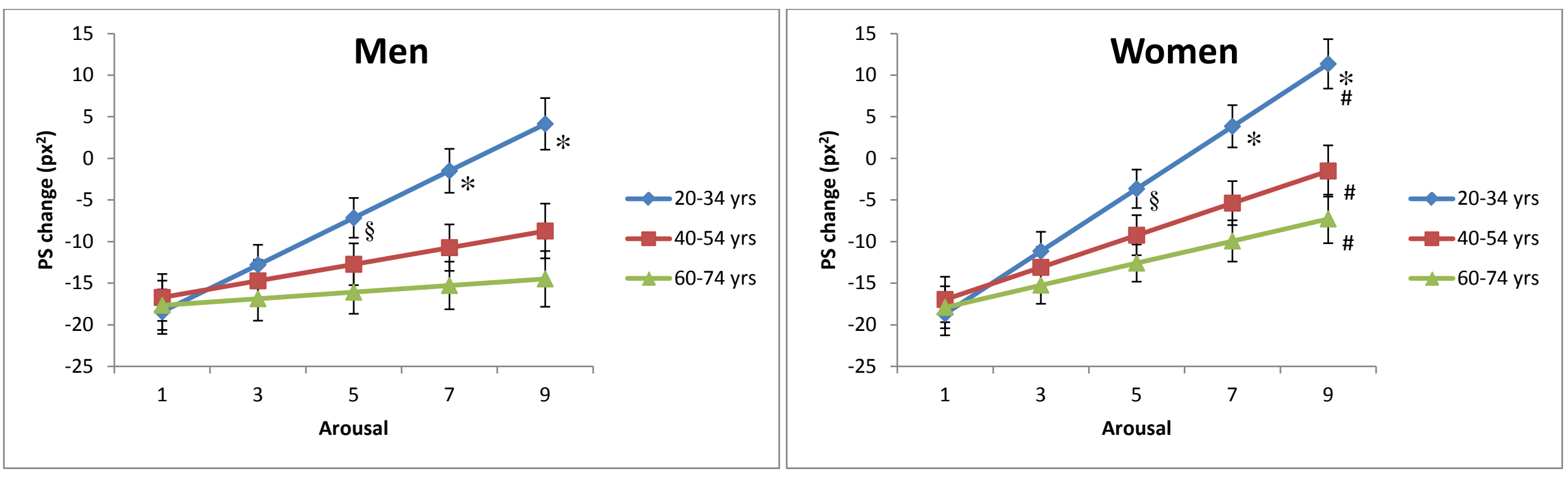

Figure 5 


\section{AUTONOMIC ACTIVATION, EMOTION, SEX, and AGING}

Figure captions

\section{Figure 1}

Model-predicted estimated marginal means (SEs) of the relationship between HR change scores and valence ratings ( $1=$ most negative valence, $9=$ most positive valence) for men (left) and women (right), by age group and adjusted for BMI and educational level (see Table 3 for predictors' estimates). * younger adults $<$ middle-aged and older adults at the same valence level $(p<.05)$; § younger adults < older adults at the same valence level $(p<.05)$; \# men $<$ women at the same valence level $(p<.05)$.

\section{Figure 2}

Contour plot showing the model-predicted estimated marginal means for SBP change scores in the space defined by valence ratings ( $1=$ most negative valence, $9=$ most positive valence) and arousal ratings ( 1 = lowest arousal, 9 = highest arousal) for men (left) and women (right) averaged across age groups and adjusted for BMI and educational level (see Table 4 for predictors' estimates). SEs range from 0.30 to 0.69 for men and from 0.26 to 0.62 for women. Compared to women, men had lower SBP change scores for the following valence-arousal combinations: 1-5, 1-7, 1-9, 3-3, 3-5, 5-1, 5-3, 7-1, 7-3, 9-1; and higher SBP changes scores for the combination 9-9 (ps <.05).

\section{Figure 3}

Contour plot showing the model-predicted estimated marginal means for DBP change scores in the space defined by valence ratings ( $1=$ most negative valence, $9=$ most positive valence $)$ and arousal ratings $(1=$ lowest arousal, 9 = highest arousal $)$ for all participants averaged across age groups and adjusted for BMI and educational level (see Table 4 for predictors' estimates). SEs range from 0.11 to 0.27 . 


\section{AUTONOMIC ACTIVATION, EMOTION, SEX, and AGING}

\section{Figure 4}

Contour plot showing the model-predicted estimated marginal means for SCL change scores in the space defined by valence ratings ( $1=$ most negative valence, $9=$ most positive valence $)$ and arousal ratings ( 1 = lowest arousal, 9 = highest arousal) for men (left) and women (right) averaged across age groups and adjusted for BMI and educational level (see Table 5 for predictors' estimates). SEs range from 0.030 to 0.050 for men and from 0.025 to 0.043 for women. Compared to women, men had lower SCL change scores for the following valencearousal combinations: 1-7, 1-9, 3-7, 3-9 (ps <.05).

\section{Figure 5}

Model-predicted estimated marginal means (SEs) of the relationship between PS change scores and arousal ratings $(1=$ lowest arousal, 9 = highest arousal) for men (left) and women (right), by age group and adjusted for BMI, educational level, and picture brightness (see Table 5 for predictors' estimates). * younger adults $>$ middle-aged and older adults at the same arousal level $(p<.05)$; $\S$ younger adults $>$ older adults at the same arousal level $(p<$ $.01)$; \# men $<$ women at the same arousal level $(p<.05)$. 